\title{
Defective Neuronal Development in the Mushroom Bodies of Drosophila Fragile X Mental Retardation 1 Mutants
}

\author{
Carlos I. Michel, ${ }^{1 \star}$ Robert Kraft, ${ }^{1 *}$ and Linda L. Restifo ${ }^{1,2}$ \\ ${ }^{1}$ Arizona Research Laboratories, Division of Neurobiology, University of Arizona, Tucson, Arizona 85721-0077, and 2Department of Neurology, Arizona \\ Health Science Center, Tucson, Arizona 85724
}

Fragile $X$ mental retardation $1(F m r 1)$ is a highly conserved gene with major roles in CNS structure and function. Its product, the RNA-binding protein FMRP, is believed to regulate translation of specific transcripts at postsynaptic sites in an activity-dependent manner. Hence, Fmr1 is central to the molecular mechanisms of synaptic plasticity required for normal neuronal maturation and cognitive ability. Mutations in its Drosophila ortholog, $d f m r l$, produce phenotypes of brain interneurons and axon terminals at the neuromuscular junction, as well as behavioral defects of circadian rhythms and courtship. We hypothesized that $d f m r 1$ mutations would disrupt morphology of the mushroom bodies (MBs), highly plastic brain regions essential for many forms of learning and memory. We found developmental defects of MB lobe morphogenesis, of which the most common is a failure of $\beta$ lobes to stop at the brain midline. A similar recessive $\beta$-lobe midline-crossing phenotype has been previously reported in the memory mutant linotte. The $d f m r 1 \mathrm{MB}$ defects are highly sensitive to genetic background, which is reminiscent of mammalian fragile-X phenotypes. Mutations of $d f m r 1$ also interact with one or more third-chromosome loci to promote $\alpha / \beta$-lobe maturation. These data further support the use of the Drosophila model system for study of hereditary cognitive disorders of humans.

Key words: metamorphosis; neurogenetics; learning; memory; cognition; genetic model system

\section{Introduction}

Fragile $\mathrm{X}$ syndrome, a very common form of inherited mental retardation (Sherman, 2002) caused by mutation of the fragile- $X$ mental retardation 1 ( Fmr1) gene, manifests as cognitive deficits, with visuospatial skills more impaired than language (Bennetto and Pennington, 2002). Some patients have epilepsy or neurobehavioral disorders, including autism (Hagerman, 2002). Regional brain defects have been detected (Kates et al., 2002), but their specificity and causality remain unresolved (O'Donnell and Warren, 2002). Single-neuron-level staining techniques reveal increased density of long, thin dendritic spines in cortical areas of fragile-X-syndrome brains (Rudelli et al., 1985; Hinton et al., 1991; Irwin et al., 2001). The abnormality suggests dendritic immaturity, implying that Fmrl is required for spine pruning and maturation during synaptogenesis (Irwin et al., 2001).

Fragile $\mathrm{X}$ syndrome typically results from expansion of a trinucleotide repeat in the $5^{\prime}$-untranslated region, followed by

\footnotetext{
Received March 24, 2004; revised May 6, 2004; accepted May 9, 2004.

This work was supported by National Institutes of Health Grant NS28495 (L.L.R.). We thank Dr. B. Hassan, Dr. T. Jongens, and Dr. T. Dockendorff for providing stocks; Dr. B. Hassan and an anonymous reviewer for insightful comments on this manuscript; Dr. K. Zinsmaier and Dr. T. Jongens for helpful discussions; C. Hedgcock, Registered Biological Photographer, for assistance with computer graphics; B. Blood for help with the P-element excision experiments; H. J. Clark for help with the lethal phase analysis of mutants; M. Kinney for help with immunostaining experiments; V. Datar for stock keeping; and M. Flood for fly food preparation.

${ }^{*}$ C.I.M. and R.K. contributed equally to this work.

Correspondence should be addressed to Dr. Linda L. Restifo, Arizona Research Laboratories, Division of Neurobiology, University of Arizona, Tucson, AZ 85721-0077. E-mail: Il@@neurobio.arizona.edu.

C. I. Michel's present address: Biology and Biomedical Sciences Program, Washington University, Campus Box 8226, St. Louis, M0 63110-1093.

DOI:10.1523/JNEUROSCI.1102-04.2004

Copyright $\odot 2004$ Society for Neuroscience $\quad 0270-6474 / 04 / 245798-\bullet \$ 15.00 / 0$
}

hypermethylation-induced transcriptional silencing of Fmr1 (Jin and Warren, 2000). The gene product, FMRP, is expressed in brain neurons (Devys et al., 1993) and binds to specific mRNAs (Brown et al., 2001; Darnell et al., 2001; Schaeffer et al., 2001), repressing their translation in vitro (Laggerbauer et al., 2001; Li et al., 2001; Mazroui et al., 2002; Zalfa et al., 2003). Indirect evidence suggests that FMRP shuttles between the nucleus and polyribosomes near synapses (Feng et al., 1997). Moreover, FMRP expression is neuronal activity-dependent in several systems (Weiler et al., 1997; Irwin et al., 2000; Todd and Mack, 2000). The evidence supports a model of FMRP as a selective regulator of postsynaptic protein synthesis involved in developmental and adult synaptic plasticity (Greenough et al., 2001; Antar and Bassell, 2003; Jin and Warren, 2003).

A mouse model, generated by transposon disruption of murine Fmr1 (Dutch-Belgian Fragile X Consortium, 1994), likewise shows cortical dendritic immaturity (Comery et al., 1997; Nimchinsky et al., 2001; Irwin et al., 2002; Galvez et al., 2003). Dendritogenesis and synaptogenesis in cultured hippocampal neurons are defective (Braun and Segal, 2000), as is long-term depression in hippocampal slices (Huber et al., 2002). Behavioral abnormalities of mutant mice are surprisingly mild (Kooy, 2003), perhaps because of functional redundancy of Fxr1 or Fxr2 (Kirkpatrick et al., 2001). Another important clue is provided by genetic background effects on behavioral (Paradee et al., 1999; Dobkin et al., 2000) and neuroanatomical (Ivanco and Greenough, 2002; Mineur et al., 2002) phenotypes.

Drosophila fmr1 (dfmr1), the sole ortholog (Wan et al., 2000), offers advantages because loss-of-function mutations are more likely to result in phenotypic defects. $d f m r 1$ mutants have abnor- 
mal circadian rhythms and courtship behavior (Dockendorff et al., 2002; Inoue et al., 2002; Morales et al., 2002). Peripheral phenotypes include overgrown, dysfunctional motor neuron terminals (Zhang et al., 2001) and overgrown sensory neuron dendritic arbors (Lee et al., 2003). In the CNS, where dFMRP is widely expressed in neurons, mutant interneurons have abnormal neurite extension, guidance, and branching (Morales et al., 2002). As for conserved molecular features, experiments in Drosophila have revealed a phosphorylation site (Siomi et al., 2002), a functionally relevant target (Kaytor and Orr, 2001; Zhang et al., 2001), and mechanisms of translational control (Caudy et al., 2002; Ishizuka et al., 2002; Jin et al., 2004).

Because mushroom bodies (MBs) are the best-characterized insect brain region involved in associative learning and memory (Heisenberg, 2003), we proposed that $d f m r 1$ regulates MB structure and function. Below we demonstrate specific developmental defects of MB morphogenesis in dfmrl mutants that are modulated by genetic interactions.

\section{Materials and Methods}

Drosophila rearing and genetics. Fly stocks were maintained at room temperature on corn meal-yeast-agar medium obtained from the Tucson Drosophila Species Stock Center (Tucson, AZ). Experimental cultures were reared at $25^{\circ} \mathrm{C}, 60-80 \%$ relative humidity, on corn flour-yeast-agar medium (Elgin and Miller, 1978). Wild-type control strains included OreRC and $w(z)$, a "Cantonized" strain of $w^{1118}$ obtained from T. Tully (Cold Spring Harbor Laboratories, Cold Spring Harbor, NY) (Bolwig et al., 1995). The $P[U A S-G F P . S 65 T]$ reporter line encoding a cytoplasmically localized, mutant green fluorescent protein (GFP) (Cubitt et al., 1995) was constructed by B. Dickson (University of Vienna, Vienna, Austria; FlyBase accession number FBrf0086268) and provided by K. Ito (University of Tokyo, Tokyo, Japan). This second-chromosome transgene was recombined onto the $P[G A L 4] 201 Y$ chromosome to produce $201 Y$ UAS-GFP, which was crossed into various backgrounds for mushroom body visualization, especially of the $\gamma$ lobes (Kraft et al., 1998). See Brand and Dormand (1995) for a description of the GAL4-UAS reporter system in Drosophila.

Mutant alleles of $d f m r 1$ [also known as Drosophila fragile-X-related $(d f x r)]$ were obtained from B. Hassan (Baylor College of Medicine, Houston, TX), who had obtained them from A. Bailey and G. Rubin (Berkeley Drosophila Genome Project, Berkeley, CA). These included $P[E P] 3517$, a P-element insertion into the second exon, which encodes $5^{\prime}$-untranslated region sequences, and three internal deletion alleles resulting from imprecise excision: $\Delta 50, \Delta 83$, and $\Delta 113$ (Zhang et al., 2001). A fourth internal deletion allele derived from $P[E P] 3517, \Delta 3$ (also called $d f m r 1^{3}$ ) (Dockendorff et al., 2002), was provided by T. Jongens (University of Pennsylvania, Philadelphia, PA). All alleles had been outcrossed for several generations. The $d f m r 1$ stocks all have a $w$-mutant $\mathrm{X}$ chromosome, and were maintained balanced over TM6B, Tb e or TM6C, Tb Sbe or $T M 3, S b e$. Standard mating procedures were used to generate transheterozygous allele combinations.

Animals were selected at readily identified stages (for metamorphosis staging criteria, see Bainbridge and Bownes, 1981): wandering third instar larva, puparium formation [white prepupa (P1)], pupation [identified by head eversion (HE) (P4ii)], or eclosion (A1). They were either dissected immediately or aged for various times. Pupal stages are given relative to head eversion, which typically takes place $\sim 12 \mathrm{hr}$ after puparium formation. Prepupae and pupae were aged at $25^{\circ} \mathrm{C}$ under highhumidity conditions as previously described (Restifo and White, 1991). We found these high-humidity conditions and the corn flour-based larval culture medium (see above) ideal for maximizing the maturational potential of developmental mutants (Restifo and White, 1991; Restifo and Merrill, 1994). A "pharate adult" stage (P14-15), within hours of adult emergence, was chosen for most analyses because brain development has reached mature adult morphology, and the lack of muscle activity and lack of air in the tracheal system allow for optimal dissection and fixation (Restifo and White, 1991).
We used the $\Delta 113$ allele to quantify the viability of mutants in two ways. On the basis of numbers of homozygous and heterozygous adults emerging from mating $\Delta 113 / \mathrm{TM} 6 \mathrm{~B}, \mathrm{~Tb} e$ males and virgin females, the viability of $\Delta 113 / \Delta 113$ was estimated at $78 \%$ compared with balancer siblings. We then conducted a lethal phase analysis in which individual prepupae of both genotypes were selected and observed throughout metamorphosis. Ninety percent of $\Delta 113 / \Delta 113$ mutants attempted eclosion ( $n=152$ ), with $\sim 80 \%$ succeeding, which was slightly better than the developmental performance of their balancer sibs. Moreover, the developmental rate of the mutant animals was normal. On the basis of these observations, most of the mutants examined during metamorphosis were alive and healthy.

We generated new excisions of $P[E P] 3517$ by standard methods (Robertson et al., 1988) and screened for precise excisions by PCR amplification using primers flanking the insertion site (data not shown). Ex(3517)-16 is one such sequence-confirmed revertant. T. Jongens also provided a line, $P\left[d f \mathrm{mrl}^{+}\right]$, carrying a wild-type genomic transgene spanning the entire $d f m r l$ transcription unit, inserted into the second chromosome (Dockendorff et al., 2002). The chromosomal deletion $D f(3 R)$ by62, which is missing cytogenetic region 85D10-11 through 85F8-11 (FlyBase accession number FBab0002716), was obtained from the Bloomington Drosophila Stock Center (over TM1, Me red e) and from T. Dockendorff (Miami University of Ohio) (over TM6C, Tb Sb e). Because recent FlyBase entries have been inconsistent about whether $D f(3 R)$ by 62 deletes $d f m r 1$, we used PCR amplification of $D f(3 R) b y 62 / \Delta 3$ genomic DNA to confirm that $d f m r 1$ sequences are indeed missing from the $D f(3 R) b y 62$ chromosome (data not shown).

Fluorescence labeling and microscopy of whole-mount brain preparations. The brains were removed in cold Drosophila buffered saline (Budnik et al., 1986) and fixed for $1-3 \mathrm{hr}$ on ice in $4 \%$ formaldehyde (Ted Pella, Redding, CA) in PBS. After three 15 min washes in PTN $(0.1 \mathrm{M}$ sodium phosphate, $\mathrm{pH} 7.2,0.1 \%$ Triton $\mathrm{X}-100$, and $0.1 \%$ sodium azide) at $4^{\circ} \mathrm{C}$, the tissue was incubated with a mouse monoclonal antibody against Fasciclin II (FasII; monoclonal antibody ID4; Developmental Studies Hybridoma Bank, Iowa City, IA) at a 1:25 dilution in PTN for $12-16 \mathrm{hr}$ at $4^{\circ} \mathrm{C}$. The tissue was washed six times for $20 \mathrm{~min}$ each at room temperature with PTN and then incubated with Cy3-conjugated goat anti-mouse secondary antisera (Jackson ImmunoResearch, West Grove, $\mathrm{PA}$ ) at a 1:1000 dilution in cold PTN for $3 \mathrm{hr}$ at $4^{\circ} \mathrm{C}$ in darkness. This was followed by six 20 min washes in PTN at room temperature in darkness. Tissue was briefly washed in $0.1 \mathrm{M}$ Tris- $\mathrm{HCl}, \mathrm{pH} 8.0$, and mounted in polyvinyl alcohol (Sigma, St. Louis, MO) with DABCO (1,4-diazabicyclo[2.2.2.] octane) (Sigma) to minimize fading of fluorescent signals (Withers and Banker, 1998). The anti-FasII staining and the GFP signal were visualized by laser-scanning confocal microscopy using a Nikon (Tokyo, Japan) PCM 2000 mounted on a Nikon E800 microscope with a $60 \times$ (numerical aperture, 1.4) oil-immersion objective and SimplePCI image acquisition software (Compix, Tualatin, OR). Preparations were scanned with a helium-neon laser line with an excitation maximum at $543 \mathrm{~nm}$ and a long-pass filter at $565 \mathrm{~nm}$ for $\mathrm{Cy} 3$ and with an argon laser line with an excitation maximum at $488 \mathrm{~nm}$ and a bandpass filter at $500-530 \mathrm{~nm}$ for GFP. The selection of subsets of optical sections for the creation of projected images was performed using SimplePCI. Images were assembled using CorelDraw 9 software (Corel, Ottawa, Ontario, Canada). Color schemes (Figs. 1, 2) were chosen to be colorblindfriendly, using the guidelines of M. Okabe and K. Ito (University of Tokyo, Tokyo, Japan) (http://jfly.iam.u-tokyo.ac.jp/color/).

Scoring and classification of mushroom body phenotypes. Brain morphology was assessed by examining individual optical sections $(z=0.5-$ $1.0 \mu \mathrm{m}$ ) of anti-FasII-labeled or $201 Y$-directed GFP-expressing brains, or both, with special attention to the mushroom body lobe and ellipsoid body regions. Note that the ellipsoid body is closely associated with the $\beta$ and $\gamma$ lobes, sitting just posterior to them, and that the ellipsoid body, which stains strongly for FasII, normally crosses the midline dorsal and ventral to the lobes (Rein et al., 2002). The $\beta$-lobe midline-crossing phenotype was classified as "severe," "moderate," "mild," or "normal," with normal brains (Fig. $1 A, B)$ showing no $\beta$-lobe fibers crossing the midline. The classification of abnormal phenotypes was based on the thickness and density of anti-FasIIlabeled $\beta$-lobe fibers crossing the midline. Severe fusion was observed as a 
densely stained band equal to or greater in width and thickness than those of the adjacent $\beta$ lobes (Fig. $1 C, D, H$ ). A moderate score was assigned when the thickness of the fiber bundle crossing the midline was considerable but less than the width of the $\beta$-lobe termini (Fig. $1 G$ ). A mild score was assigned when a thin band of fibers crossed the midline; this phenotype was often very subtle and only apparent in a few optical sections (Fig. $1 F$ ). Mild phenotypes might easily be missed with lower-resolution methods. $\beta$-lobe crossing was usually bilaterally symmetric, but occasionally a band of fibers appeared to extend from only one $\beta$ lobe and traverse the midline, e.g., when the other $\beta$ lobe was missing or not projecting in the normal medial direction (see below). When midline crossing was observed from a single $\beta$ lobe, the phenotype severity was scored according to the above criteria.

Accessory mushroom body phenotypes of pharate adults were defined as instances of gross $\alpha$ - or $\beta$-lobe dysmorphology, with one or more lobes apparently missing or misdirected. A mushroom body immaturity phenotype, also assessed by anti-FasII labeling and identified in association with $D f(3 R) b y 62$, consisted of lobe morphology in a pharate adult brain resembling normal mushroom bodies at considerably earlier developmental stages. In particular, lobe diameter was unusually thin and variable along the length of the lobes. The phenotype was scored as severe, moderate, or "within normal limits" (WNL) on the basis of the degree to which mushroom body lobe maturity deviated from that observed in the wild type at the same developmental stage (see Fig. $5 A-C$ ). This phenotype was scored blind with respect to genotype.

\section{Results}

dfmr1 mutants have a mushroom body $\boldsymbol{\beta}$-lobe midline-crossing phenotype

The MBs are paired neuropils arranged symmetrically about the midline of the brain. In wild-type Drosophila melanogaster, axon-like fibers in the medially projecting lobes terminate near the midline but do not cross it (Strausfeld et al., 2003). We identified MB structural phenotypes in $d f m r 1$ mutants by immunostaining for FasII of whole brains dissected from pharate adults. As previously described for sectioned material (Crittenden et al., 1998), confocal microscopy reveals strong immunolabeling of $\alpha / \beta$ neurons along the peduncles as well as distally as their axons bifurcate and project dorsally into the $\alpha$ lobes and medially into the $\beta$ lobes. Weaker anti-FasII labeling is seen in $\gamma$ neurons which are unbranched and project medially into the $\gamma$ lobes (Fig. $1 A, E)$. In contrast to wild-type MB morphology, brains of $d f m r 1$ mutants show $\beta$ lobe fibers extending across the midline, sometimes sufficient to cause apparent fusion of the right and left $\beta$ lobes (Fig. 1C). Using GAL4-201Y and a UAS-GFP reporter (see Materials and Meth-
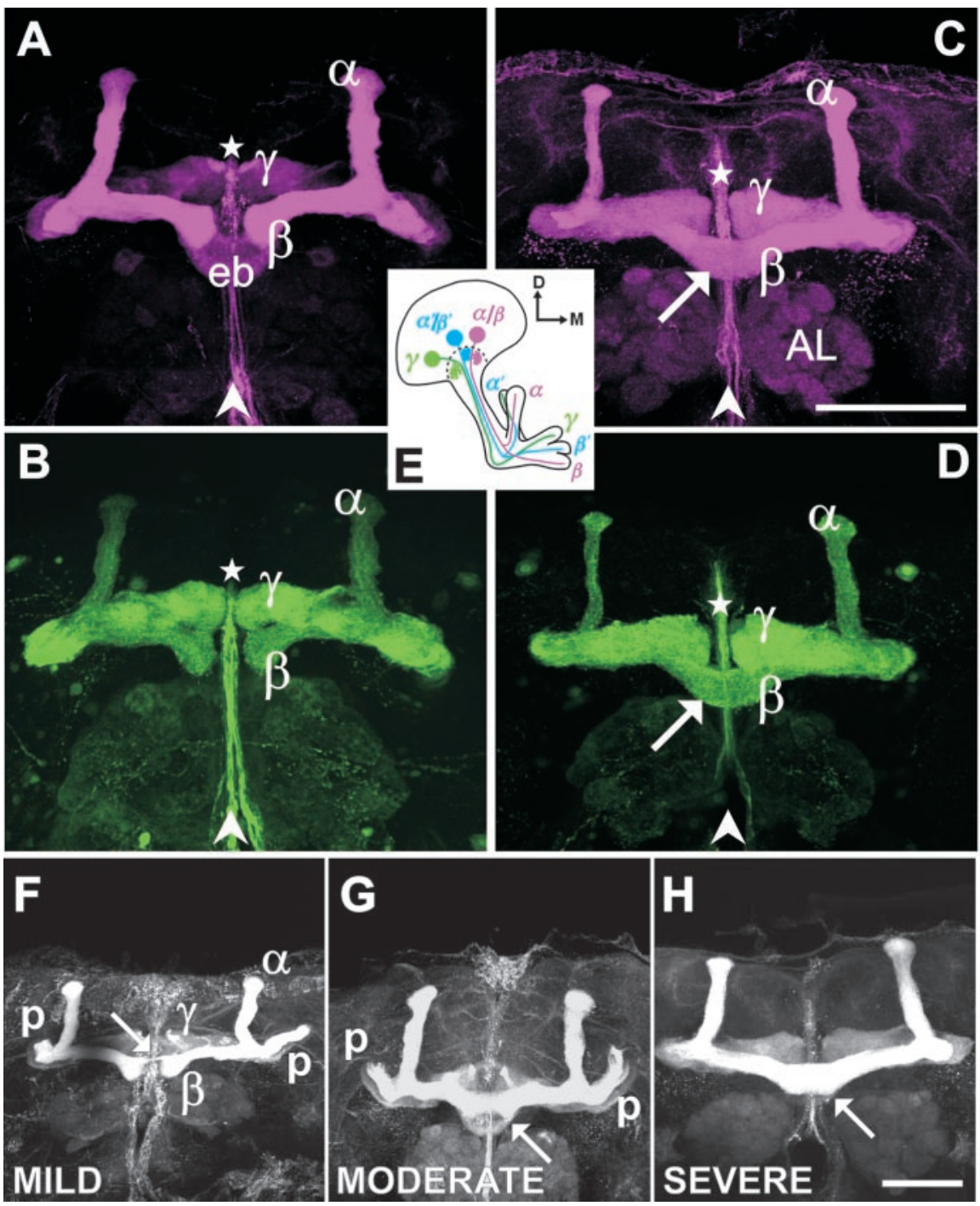

Figure 1. Mutations in $d f m r 1$ cause $M B \beta$-lobe fibers to cross the brain midline: Iobe specificity and variable expressivity. $A-D$, Projections of sequential optical sections through the MB lobe regions from two pharate adult whole-mount brain preparations. Frontal views; dorsal is at the top. Fasll expression, which is strong in the $\alpha$ and $\beta$ lobes and weaker in the $\gamma$ lobes, is detected by immunostaining and is shown as magenta $(A, C$. Fasll is also expressed in the ellipsoid body (eb) of the central complex, which is centered about the brain midline (arrowhead) immediately posterior to the medially directed MB lobes. The antennal lobes (AL) stain weakly for FasIl. GFP reporter expression driven by GAL4-201Y, which is strong in the $\gamma$ lobes and weaker in $\alpha$ and $\beta$ lobes, is shown as green $(B, D)$. Stars indicate processes of the median bundle extending along the brain midline from cell bodies in the pars intercerebralis that are positive for both Fasll and GFP (Ito et al., 1997). A, B, Wild-type (201Y UAS-GFP/+) MB lobes exhibiting normal morphology. $\beta$ and $\gamma$ lobes terminate adjacent to the brain midline without crossing it. $C, D, d f m r 1$ mutant (201Y UAS-GFP/+; $\Delta 83 / \Delta 83$ ) MB lobes. $\beta$-lobe fibers crossing the brain midline (arrow) are visualized by both anti-Fasll ( $C$ ) and GFP $(D)$. However, the $\gamma$ lobes appear normal and do not extend across the midline. The somewhat higher-than-normal Fasll labeling intensity of mutant $\gamma$ lobes $(C)$ is occasionally seen in dfmr 1 mutants. E, Diagram of wild-type adult mushroom body, left side only (adapted from Crittenden et al., 1998). D, Dorsal; M, medial. A single representative of each of the three major subtypes of Kenyon cells $\left(\gamma, \alpha^{\prime} / \beta^{\prime}, \alpha / \beta\right)$ is shown projecting a dendritic arbor within the calyx and an axon-like process through the peduncle and into its respective lobe(s). The relative positions of the neuronal cell bodies are not intended to imply anatomical segregation of the three types. $F-H$, Projection of sequential optical sections through the $\alpha$ and $\beta$ lobes, visualized by Fasll immunostaining, showing representatives of the phenotypic categories used in scoring $\beta$-lobe midline crossing. Frontal views; dorsal is at the top. The distal end of the peduncle $(p)$, composed of axonal projections from the neuronal cell bodies to the MB lobes, is visible in Fand G.F, Mild (P[EP]3517/P[EP]3517). A thin band of $\beta$-lobe fibers crosses the midline, linking the dorsal-most regions of right and left lobes (arrow). G, Moderate $(\Delta 113 / T M 6 B)$. The $\beta$-lobe fiber bundle crossing the midline is substantial (arrow) but less than the thickness of the $\beta$-lobe termini. $H$, Severe $(\Delta 50 / \Delta 113)$. A densely stained band (arrow) equal to or greater in thickness than the $\beta$ lobes extends across the midline; the lobes appear fused. Scale bars: $A-D, F-H, 50 \mu \mathrm{m}$.

ods) to visualize the $\gamma$ lobes (Fig. $1 B, D$ ), it was evident that $d f m r 1$ mutant $\gamma$-lobe fibers do not extend across the brain midline (Fig. $1 D)$. In other words, $d f m r 1$ mutations cause a selective defect in MB morphology involving neurons born during metamorphosis, 
whereas their $\gamma$-neuron neighbors, which are regenerating in close proximity at the same time (Lee et al., 1999), are unaffected.

Because the $\beta$-lobe midline-crossing phenotype was variable in degree, we developed a classification scheme based on the apparent fraction of $\beta$-lobe axons that cross the midline (see Materials and Methods) (Fig. $1 F-H)$. Several $d f m r 1$ mutant alleles were examined either as homozygotes or as transheterozygotes, including the P-element insertion allele, $P[E P] 3517$, and four internal deletions, $\Delta 83, \Delta 3, \Delta 113$, and $\Delta 50$, derived by imprecise excision (Fig. $2 F$ ). With the exception of $\Delta 50$ homozygotes, many of which could not be scored (see below), the penetrance and expressivity of the $\beta$-lobe midline-crossing phenotype was high for all mutant genotypes tested, with $>60 \%$ of brains showing severe midline crossing (Fig. $2 \mathrm{~A}$ ). Within a given genotype, there was no sexual dimorphism in penetrance or expressivity (data not shown). Although there was some variation in penetrance and expressivity among the alleles, there was no difference between the hypomorphic insertion allele, $P[E P] 3517$, which has reduced protein expression (Morales et al., 2002) and $\Delta 3$, the largest deletion allele, which must be protein-null (Dockendorff et al., 2002). MBs of newly eclosed or 2-d-old adult dfmr 1 homozygous mutants also showed $\beta$-lobe midline crossing in a majority of animals (see below).

In OreRC, a wild-type laboratory strain, we found a very low incidence and severity of $\beta$-lobe midline crossing: $7 \%$ mild and $7 \%$ moderate (Fig. 2 B), which is similar to other analyses based on brain sections (Moreau-Fauvarque et al., 1998) and consistent with the occasional wild-type $\beta$-lobe axon seen crossing the midline in Golgi preparations (N. J. Strausfeld, personal communication). When $\Delta 83$ was placed over a wild-type third chromosome from an OreRC parent, the resulting heterozygotes showed no midline crossing (Fig. $2 C$ ). Similarly, $\Delta 113$ over a wild-type third chromosome from one of several sources showed normal $\beta$-lobe morphology (data not shown). Balancer siblings from the $d f m r 1$ mutant stocks had either normal $\beta$ lobes or a low incidence of midline crossing (Fig. 2C). Hence, the $\beta$-lobe midline-crossing phenotype is recessive.

\section{The $\boldsymbol{\beta}$-lobe midline-crossing phenotype maps to $\mathrm{dfmr} \mathbf{I}$}

Approximately $70 \%$ of $P[E P] 3517$ homozygous brains exhibited $\beta$-lobe midline crossing, with a great majority having a severe phenotype. If the phenotype results from P-element insertion into the $d f m r 1$ gene, then the precise excision of this transposon should rescue $\beta$-lobe morphology. Excision lines were generated by standard procedures, and several independent precise excisions of the P element were identified by PCR amplification using primers flanking the insertion site (data not shown). Examination of the brains of homozygous precise-excision animals showed phenotypic reversion to wild-type or near-wild-type levels (Fig. 2B). For example, Ex(3517)-16 homozygotes had 14\% $\beta$-lobe midline crossing but only of the mild or moderate class. This is comparable with the frequency and severity of the phenotype in OreRC (Fig. $2 B$ ).

In a parallel approach to mapping the $\beta$-lobe midlinecrossing phenotype, we provided a single wild-type copy of $d f m r 1$ $\left(P\left[\mathrm{dfmr} \mathrm{I}^{+}\right]\right)$to mutant transheterozygotes. To be able to compare siblings, we crossed $w ; P\left[d f m r 1^{+}\right] ; \Delta 3 / T M 6 C, T b S b$ e to either $w ;+/+; \Delta 83 / \Delta 83$ or $w ;+/+; \Delta 113 / \Delta 113$. Each experiment yielded transheterozygous siblings $(\Delta 3 / \Delta 83$ or $\Delta 3 / \Delta 113$, respectively) that differed by the presence or absence of the wild-type $d f m r 1$ transgene, which was detectable because of the effect of mini- $w^{+}$on eye color. For both $\Delta 3 / \Delta 83$ and $\Delta 3 / \Delta 113$, the presence of a single wild-type $d f m r 1$ transgene greatly reduced the penetrance and expressivity of the $\beta$-lobe midline-crossing phenotype (Fig. 2D). Together, the phenotypic reversion after P-element excision and the partial rescue by a single copy of $d f m r 1^{+}$demonstrate that $\beta$-lobe midline crossing maps to the $d f m r 1$ gene. This MB phenotype is very similar to that of the mutant linotte (Moreau-Fauvarque et al., 1998; Simon et al., 1998), originally identified because of a memory phenotype (Dura et al., 1993).

Given the high penetrance and expressivity of the $\beta$-lobe midline-crossing phenotype of $d f m r 1$ mutants, it is surprising that other investigators did not detect it using anti-FasII immunostaining (Dockendorff et al., 2002). Potential contributors to this discrepancy include both technical and biological issues. First, if lower-resolution microscopy methods were used, it would have been possible to confuse $\beta$-lobe midline crossing with the normal morphology of the adjacent ellipsoid body or simply to miss a mild phenotype. Second, because there is some late-pupal lethality of $d f m r 1$ mutants (see Materials and Methods), the penetrance and severity of MB phenotypes in adults may be lower than in pharate adults. Our observation that only $42 \%$ of 2 -d-old $d$ fmr 1 homozygous mutants have severe $\beta$-lobe midline crossing (compare Fig. $2 A, E$ ) is consistent with this idea. Finally, there could be spontaneous "correction" of $\beta$-lobe defects after eclosion, analogous to the report of transient abnormalities of cortical dendritic development in fmrl mutant mice (Nimchinsky et al., 2001). However, we consider this very unlikely because the overall penetrance of $\beta$-lobe midline crossing in 2 -d-old adult mutants is very high, $79 \%(n=19)$.

\section{Genetic background strongly affects the penetrance of $\beta$-lobe midline crossing}

The normal $\beta$-lobe morphology of $\Delta 83 /+$ brains demonstrates the recessive nature of the midline-crossing phenotype. Nonetheless, the modest penetrance of the phenotype in balancer siblings ( $\leq 30 \%$ ) (Fig. 2C) was noteworthy. Moreover, when we replaced the third chromosome balancers to create $d f m r 1$ stocks for different purposes, we noticed wide variation in the midline-crossing phenotype among balancer heterozygotes. These observations suggested the possibility of an interaction between $d f m r 1$ mutations and other sites on the third chromosome. To test this directly, we mated $\Delta 83 / T M 6 B, T b$ e to $\Delta 83 / T M 3, S b$ e and examined three classes of progeny siblings for the frequency and severity of $\beta$-lobe midline crossing (Fig. $2 E$ ). As previously, $\Delta 83$ / $\Delta 83$ brains showed $100 \%$ penetrance, the vast majority of which was severe, and $\Delta 83 / T M 6 B$ showed $30 \%$ penetrance, most of which was mild and moderate. However, $\Delta 83 / T M 3$ brains showed $90 \%$ penetrance, and $90 \%$ of that was severe. In other words, in the presence of the TM3 balancer, the $d f m r 1 \beta$ lobe midline-crossing phenotype becomes dominant. A similar enhancement was seen with the TM1, Me red e third chromosome balancer (data not shown). Thus, the $\beta$-lobe midline-crossing phenotype caused by $d f m r 1$ mutations is highly susceptible to genetic background effects, as is the hippocampal phenotype of Fmr1 mutant mice (Ivanco and Greenough, 2002; Mineur et al., 2002).

\section{Development of the $\boldsymbol{\beta}$-lobe midline-crossing phenotype during metamorphosis}

The $\alpha / \beta$ Kenyon cells are born during the first half of metamorphosis; as they differentiate, each neuron extends an axon-like process that branches into the ipsilateral $\alpha / \beta$ lobes (Lee et al., $1999)$. Given the neurite overgrowth phenotypes previously reported in $d f m r 1$ mutants (Zhang et al., 2001; Dockendorff et al., 2002; Morales et al., 2002), the midline-crossing phenotype in 


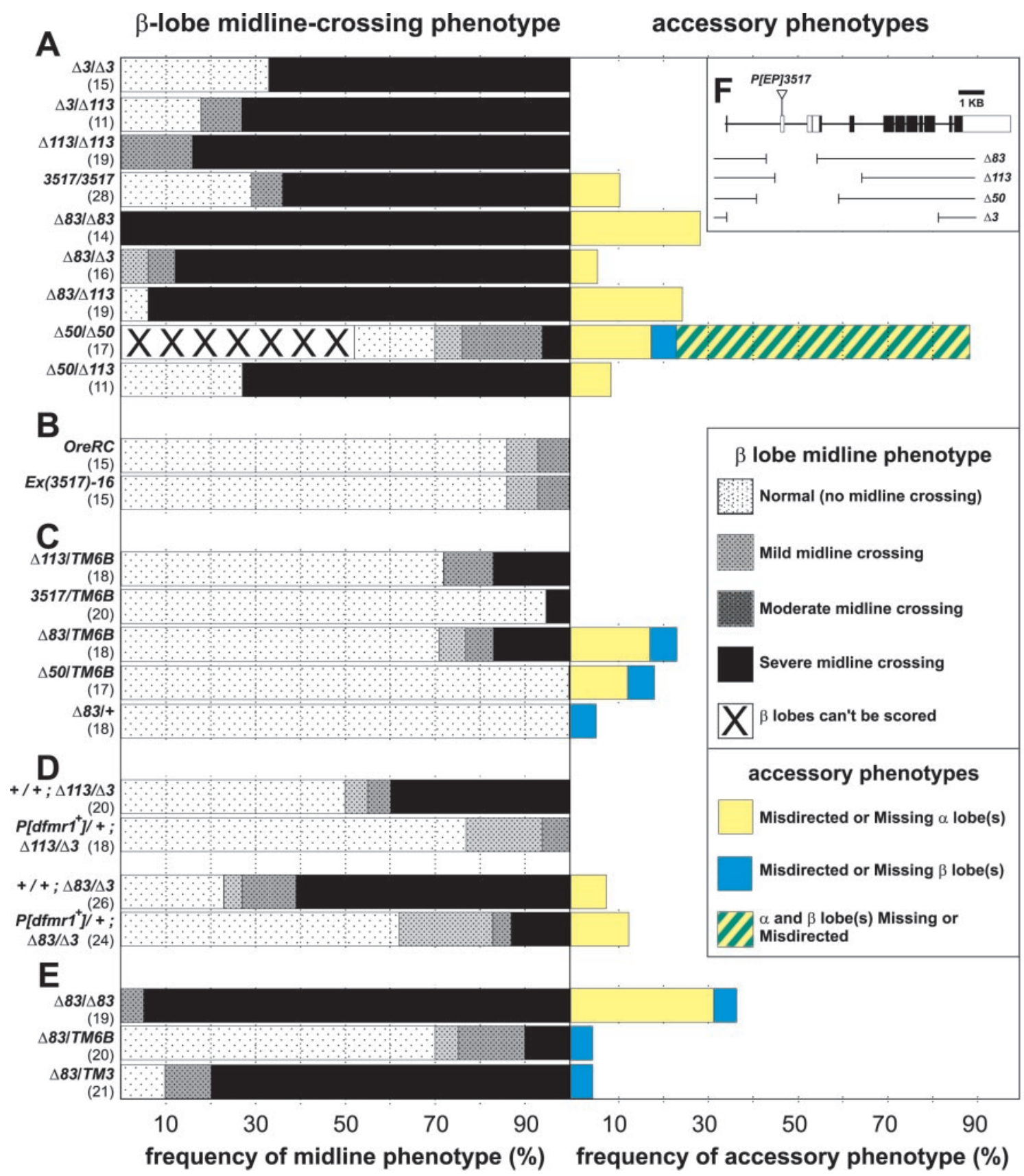

Figure 2. Penetrance and expressivity of the mushroom body phenotypes in pharate adult brains of various genotypes. For each genotype, the $\beta$-lobe midline-crossing phenotype is depicted in gray scale on the left of the graph, and accessory phenotypes are shown color-coded on the right (see boxed legend). The number of samples analyzed is shown in parentheses. $A$, Homozygous and transheterozygous dfmr 1 mutants. Penetrance and expressivity of $\beta$-lobe midline crossing are very high. Accessory phenotypes have much lower penetrance and are limited to a subset of alleles. $B$, Comparison of the wild-type strain OreRC and the precise-excision line $E x(3517)-16$. Precise excision has normalized both midline-crossing and accessory phenotypes. $C$, Heterozygotes. The TM6B-bearing animals were all siblings of homozygotes or transheterozygotes shown in $A$. The wild-type + chromosome came from OreRC. Heterozygotes show much less, if any, $\beta$-lobe midline crossing than do homozygous and transheterozygous mutants, but accessory phenotypes persist in the presence of $\Delta 50$ and $\Delta 83$ alleles. $D$, Results from two rescue experiments using the genomic transgene $P\left[d f m r 1^{+}\right]$; each pair of samples represents siblings derived from a cross. A single wild-type copy of dfmr $1^{+}$greatly improves the midline-crossing phenotypes of both $\Delta 83 / \Delta 3$ and $\Delta 113 / \Delta 3$ mutants. However, the accessory phenotypes associated with $\Delta 83$ are not reduced. $E$, Three sibling classes from the mating of $\Delta 83 / T M 6 B$ to $\Delta 83 / T M 3$ demonstrate the effect of different balancers on the midline-crossing phenotype. These samples are independent of those of the same genotype shown in other parts of this figure. $F$, Diagrammatic representation of the $d f m r 1$ locus (modified from Zhang et al., 2001; Dockendorffet al., 2002). The exons are depicted as boxes (or as a line in the case of the very small exon 1) aligned in their approximate positions along the genomic sequence, with noncoding regions in white and coding regions in black. The insertion site of the P-element allele $P[E P] 3517$ into the second exon is shown, as are the approximate sizes of the internal deletions of four alleles $(\Delta 83, \Delta 113, \Delta 50, \Delta 3)$ generated by the imprecise excision of $P[E P] 3517$.

dfmr1 mutant MBs at the end of metamorphosis might result from failure of $\beta$-lobe axons to terminate their growth as they approach the midline, thus extending into the contralateral $\beta$-lobe region. An alternative possibility is that wild-type $\beta$-lobe axons transiently cross the midline during their initial outgrowth and are subsequently pruned back, with the $d f m r 1$ mutant phenotype reflecting failure of branch pruning. To resolve this question, we compared $\mathrm{MB}$ development in wild-type and mutant brains, using $\Delta 83$ homozygotes because they manifest complete penetrance of the midline-crossing phenotype, and several differ- 
ent control genotypes, including $201 Y$ UAS-GFP/+, $w(z)$ and $\Delta 83 / T M 6 B$.

First, we used the $201 Y$ driver to show that the medial lobes of late larval $\gamma$ neurons in $\Delta 83$ or $\Delta 113$ homozygous mutant MBs $(n=20)$ do not cross the midline (data not shown). Moreover, retraction of vertical and medial branches of $\gamma$ neurons occurs on schedule and to its full extent in young mutant pupae $(n=6)$ (data not shown). Given the normal midline phenotype of mutant larval and young pupal $\gamma$ neurons, the late-stage $\beta$-lobe midline-crossing phenotype cannot be blamed on faulty $\gamma$-neuron morphology earlier in development. Second, we used FasII immunostaining to track the development of $\alpha / \beta$ neurons. In wild-type pupae at $\mathrm{HE}+16-17 \mathrm{hr}$, the $\alpha$ and $\beta$ lobes appear as thin bundles projecting dorsally and medially (Fig. $3 A$ ). These bundles lengthen and thicken over the next several hours, and by $\mathrm{HE}+22 \mathrm{hr}$, the tips of the $\beta$ lobes reach their maximum medial extension, approaching but not crossing the brain midline (Fig. $3 C)$. The appearance is similar at $\mathrm{HE}+24 \mathrm{hr}$, except for a slight enlargement of lobe diameter (Fig. $3 E$ ). Over the next $24 \mathrm{hr}$, the two lobes continue to increase in diameter as fibers of newly born $\alpha / \beta$ neurons are added (Fig. $3 G$ ). Between 48 and $72 \mathrm{hr}$ after HE, $\alpha / \beta$ lobes resemble their appearance in the pharate adult (data not shown). We saw no evidence in the wild type of transient midline crossing of $\beta$-lobe fibers.

In $\Delta 83 / \Delta 83$ mutant brains, the $\alpha$ and $\beta$ lobes also appear as thin FasII-immunoreactive bundles at $\mathrm{HE}+16-17 \mathrm{hr}$ (Fig. $3 B$ ), with progressive thickening over the next $30 \mathrm{hr}$. The medial tips of the $\beta$ lobes approach the midline at the correct time $(\mathrm{HE}+22$ hr) (Fig. 3D), but immediately thereafter, fibers can be seen to extend from the $\beta$-lobe termini across the midline (Fig. $3 F$ ). By $48 \mathrm{hr}$, the right and left $\beta$ lobes appear fused and very similar to the pharate-adult mutant phenotype (Fig. $3 H$ ). Thus, the midline-crossing phenotype is attributable to $\beta$-lobe axons failing to stop at the normal lobe terminus and, instead, growing across the brain midline into the contralateral $\beta$ lobe. Consistent with what we saw in the pharate adults, the phenotype usually develops symmetrically.

Accessory mushroom body phenotypes of $d f m r 1$ mutants In addition to the high-penetrance, recessive $\beta$-lobe midlinecrossing phenotype of $d f m r 1$ mutants, other MB abnormalities were observed at low frequency with some alleles (Figs. 2, 4). These accessory phenotypes most often involve the $\alpha$ lobe, but $\beta$-lobe involvement was occasionally seen as well. There were two general varieties of accessory phenotypes: lobe(s) missing or lobe(s) misdirected. For ease of graphical display (Fig. 2), we grouped "missing" and "misdirected" accessory phenotypes but separated them according to which lobes were involved. Note that the combination of highly penetrant $\beta$-lobe midline crossing and low-penetrance $\alpha$-lobe-missing has been previously reported in the memory mutant linotte (Simon et al., 1998). Because the accessory phenotypes could be found in the absence of $\beta$-lobe midline crossing, we consider them independent phenotypes. Of course, in the extreme case of both $\beta$ lobes missing or misdirected (as in some $\Delta 50$ homozygotes), the midline phenotype cannot be scored.

The accessory phenotypes are dramatic and very diverse. In some brains, the aberrant $\alpha$ or $\beta$ lobe appeared to project parallel to its ipsilateral $\beta$ or $\alpha$ lobe, respectively (Fig. $4 A-C$ ). In other words, the $\alpha / \beta$ axons had branched, but the two bundles projected side by side either vertically or medially. In other preparations with an apparently missing lobe, the remaining ipsilateral lobe was much thicker than normal, suggesting that $\alpha / \beta$-lobe
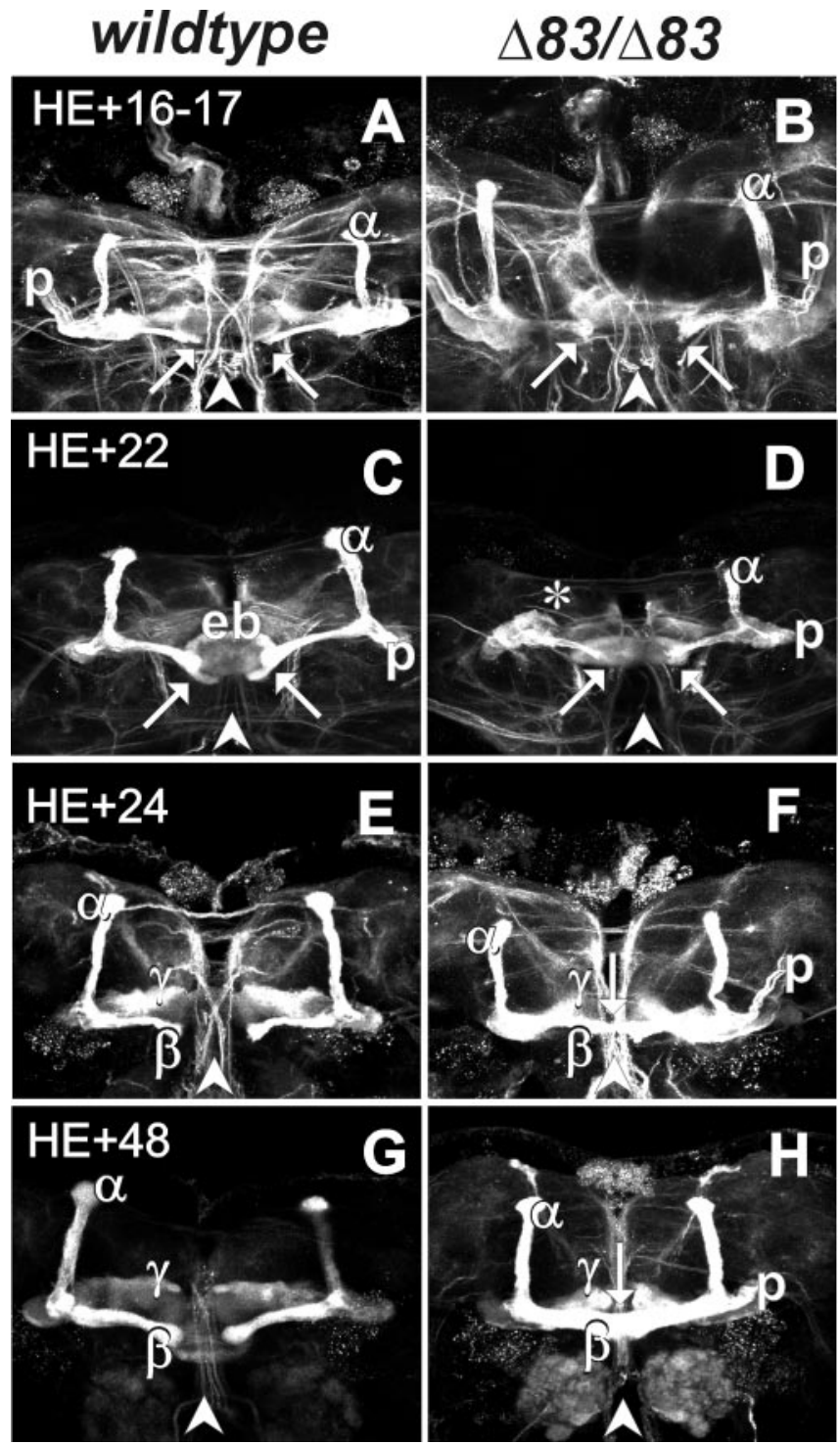

Figure 3. The $\beta$-lobe midline-crossing phenotype in dfmr 1 mutants develops during metamorphosis. Projection of sequential optical sections through the MB lobe regions at successive stages during metamorphosis is shown. Times indicated are hours after $\mathrm{HE}$, the beginning of the pupal period. The $\alpha$ and $\beta$ lobes were visualized by Fasll immunostaining, which also labels many other pathways, especially during early pupal development. Frontal views; dorsal is at the top. The distal end of the peduncle ( $p$ ) is visible in some images. The white arrowheads indicate the position of the brain midline. Pairs of images compare wild-type in the left column $(A, C, E$, G) with $\Delta 83 / \Delta 83$ mutants in the right column $(B, D, F, H)$ at the same developmental stage. $A$, $B, \mathrm{HE}+16-17 \mathrm{hr}$. In both wild-type (201Y UAS-GFP/+) and mutant brains, the medial tips of the $\beta$ lobes (arrows) can be seen approaching the midline. The lobes are thin relative to their mature morphology. The apparent length difference between the wild-type $(A)$ and mutant ( $B) \alpha$ lobes is attributable to differences in the orientation of the samples during mounting. $C$, $D, \mathrm{HE}+22 \mathrm{hr}$. Wild-type $[w(\mathrm{z})]$ and mutant $\beta$-lobe termini are adjacent to the midline (arrows). In $C$, the image of the $\beta$-lobe termini is projected onto part of the ellipsoid body (eb). The wild-type $\alpha / \beta$ lobes have thickened compared with earlier stages. $D$, In the mutant, $\alpha / \beta$-lobe growth is somewhat delayed, and the left $\alpha$ lobe (asterisk) is misdirected out of the plane of the image. (For additional examples of $\alpha$-lobe misdirection, see Fig. 5.) The apparent reduced length of the right $\alpha$ lobe is attributable to variation in sample mounting. $E, F, \mathrm{HE}+24 \mathrm{hr}$. The $\gamma$ lobes have become Fasll-positive and can be seen adjacent to the midline in both wild-type and mutant brains. $E$, The wild-type (201Y UAS-GFP/+; $\Delta 83 / T M 6 B) \alpha / \beta$ lobes look similar to those at the previous stage. $F$, In the mutant (201Y UAS-GFP/ $; \Delta 83 / \Delta 83), \beta$-lobe fibers have crossed the midline (arrow), with the fused region almost as thick as the adjacent $\beta$ lobes. $G, H$, $\mathrm{HE}+48 \mathrm{hr}$. G, Wild-type (201Y UAS-GFP/+; $\Delta 83 / T M 6 B) \alpha / \beta$ lobes are nearing maturation, although they are still thinner than in the adult. $H$, The mutant brain (201Y UAS-GFP/+; $\Delta 83$ / $\Delta 83$ ) shows severe $\beta$-lobe midline crossing (arrow), with full fusion of right and left sides. 

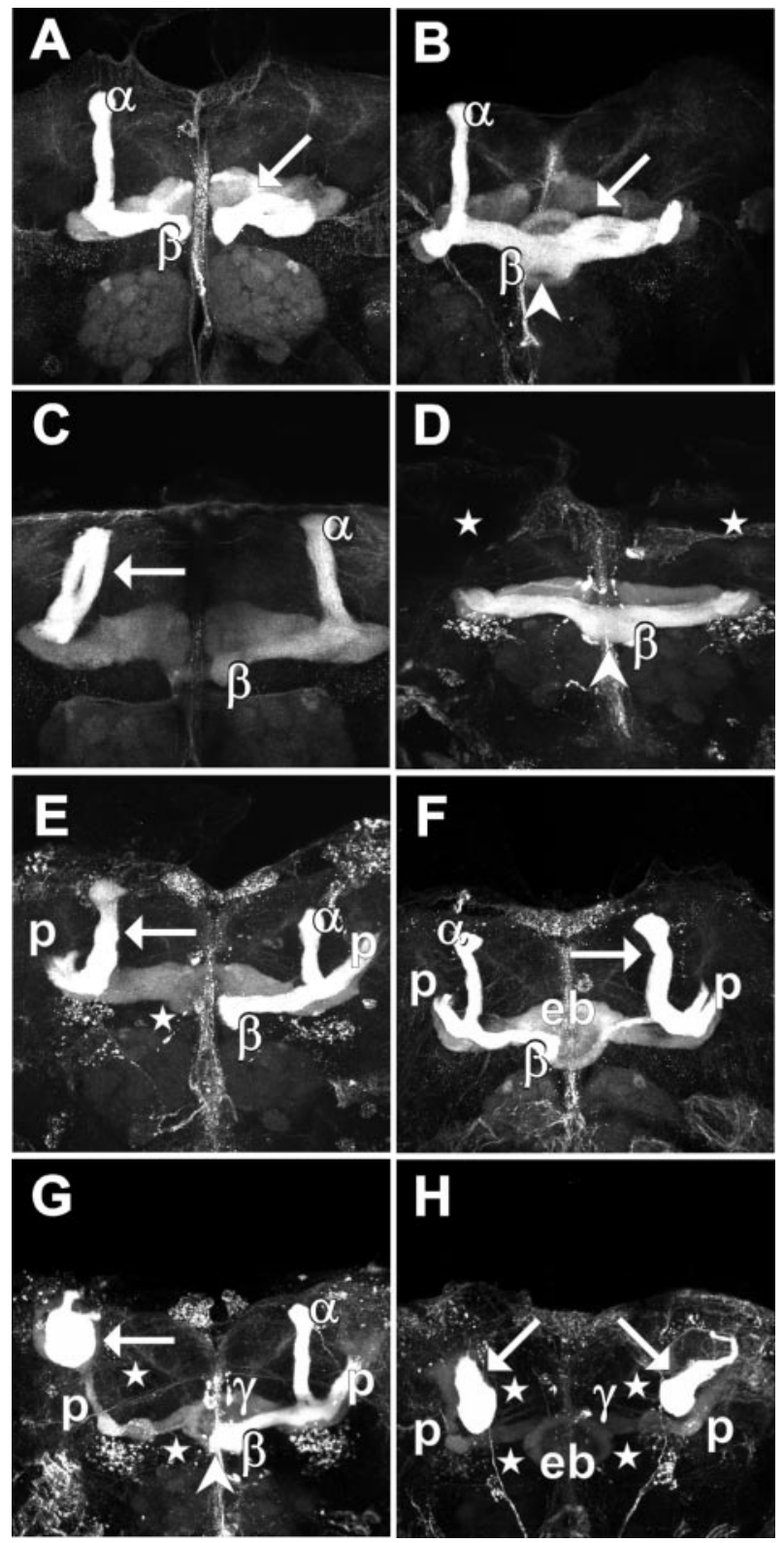

Figure 4. Accessory phenotypes of the MB $\alpha$ and $\beta$ lobes associated with some dfmr 1 alleles. Projections of sequential optical sections through the MB lobe regions of Fasllimmunostained pharate adult brains (except $C$, which is from a 2-d-old adult) are shown. Frontal views; dorsal is at the top. $A, \alpha$ lobe misdirected without $\beta$-lobe midline crossing $(\Delta 83 / T M 6 B)$. The right $\alpha$ lobe projects parallel to the ipsilateral $\beta$ lobe (arrow). $B, \alpha$ lobe misdirected with $\beta$-lobe midline crossing ( $\Delta 3 / \Delta 83)$. The right $\alpha$ lobe projects parallel to the ipsilateral $\beta$ lobe (arrow). The $\beta$ lobes are virtually fused across the midline (arrowhead). C, $\beta$ lobe misdirected ( $\Delta 83 / \Delta 83)$. The left $\beta$ lobe projects parallel to the ipsilateral $\alpha$ lobe (arrow). The contralateral $\alpha / \beta$ lobes appear morphologically normal. $D, \alpha$ lobes missing with $\beta$-lobe midline crossing ( $\Delta 50 / \Delta 50)$. Neither $\alpha$ lobe is present (stars), and the $\beta$ lobes are fused across the midline (arrowhead). $E, \beta$ lobe missing $(\Delta 50 / \Delta 50)$. The left $\beta$ lobe is not present in its normal location (star), and the ipsilateral $\alpha$ lobe is thicker than usual (arrow), suggesting $\beta$ lobe misdirection and $\alpha / \beta$-lobe fusion. $F$, $\beta$ lobe reduced, with probable partial misdirection ( $\Delta 83$ / TM3). The right $\beta$ lobe is greatly reduced in thickness; its image is projected onto the ellipsoid body (eb). The ipsilateral $\alpha$ lobe is enlarged (arrow) relative to the contralateral one, suggesting that part of the right $\beta$ lobe is misdirected vertically and fused with the $\alpha$ lobe. $G, \alpha$ and $\beta$ lobes missing unilaterally, with contralateral $\beta$-lobe midline crossing $(\Delta 50 / \Delta 50)$. Fasll-immunoreactive mushroom body fibers have formed a large clump (arrow) ipsilateral to the missing lobes (stars). The weakly labeled fibers represent the peduncle ( $p$ ) and the $\gamma$ lobe. On the contralateral side, $\beta$-lobe fibers cross over the midline a short distance (arrowhead). $H, \alpha$ and $\beta$ lobes missing bilaterally $(\Delta 50 / \Delta 50)$. № recognizable $\alpha$ or $\beta$ lobes are visible (stars), but the peduncles and $\gamma$-lobe fibers are present. Fasllimmunoreactive mushroom body fibers form large clumps bilaterally (arrows). fusion had occurred (Fig. 4E,F). In cases of a missing lobe without evidence of misdirection (Fig. $4 D$ ), it is possible that $\alpha / \beta$ axons failed to branch at the bottom of the peduncle and then selected one of two possible projection paths to generate a single $\alpha$ or $\beta$ lobe. It is also possible that all missing lobes are really misdirected but that we were not always able to discern the path or location of the misdirected lobe (Fig. 4G,H). It is worth considering the detection sensitivity for accessory phenotypes, especially compared with the $\beta$-lobe midlinecrossing phenotype. If a small subset of $\alpha / \beta$ neurons had misdirected projections, e.g., both branches projecting medially within the $\beta$ lobe, this might be very difficult to detect by our methods. Nor would single-neuron analyses such as Golgi impregnations (Strausfeld et al., 2003) or MARCM (mosaic analysis with a repressible cell marker) clones (Lee and Luo, 1999) reliably find such defects if they affected a small percentage of $\alpha / \beta$ neurons. Hence, our analysis may underestimate the true penetrance of accessory phenotypes. In all cases in which accessory phenotypes were observed in pharate adults, both $\gamma$ lobes were present, albeit somewhat reduced in size in the most severely affected MBs, and projected in the normal medial direction.

The accessory phenotypes are also striking because of their genotype distribution and mode of inheritance (Fig. 2). The Pelement insertion allele $P[E P] 3517$ had a low incidence $(\sim 10 \%)$ of accessory phenotypes, and these were eliminated when the $\mathrm{P}$ element was excised precisely (Fig. $2 A, B$ ). The penetrance and expressivity of accessory phenotypes of $\Delta 50$ homozygotes were exceptionally high. Accessory phenotypes were seen with all $\Delta 83$ or $\Delta 50$ genotypes, including $\Delta 83$ and $\Delta 50$ homozygotes and, with lower penetrance, in any transheterozygous mutants with one of those alleles (i.e., $\Delta 50 / \Delta 113, \Delta 83 / \Delta 3$, and $\Delta 83 / \Delta 113$ ) (Fig. $2 A, E$ ) and $\Delta 83 / D f(3 R) b y 62$ (see below). Moreover, they were seen in $\Delta 83$ and $\Delta 50$ heterozygotes in which the other third chromosome was wild type for $d f m r 1(\Delta 83 /+$, where + came from OreRC, $\Delta 83 / T M 6 B, \Delta 83 / T M 3$, and $\Delta 50 / T M 6 B)$, even in the absence of the $\beta$-lobe midline-crossing phenotype (Fig. $2 C, E$ ). In the genomic rescue experiment with $\Delta 83 / \Delta 3$ (Fig. $2 D$ ), the $d f m r 1^{+}$ transgene reduced the frequency of $\beta$-lobe midline crossing, but the accessory phenotypes were still present at an unimproved frequency. In contrast, $\Delta 3$ and $\Delta 113$ homozygotes, and $\Delta 3 / \Delta 113$ transheterozygotes never displayed accessory phenotypes. In other words, the accessory phenotypes are restricted to a subset of $d f m r 1$ alleles and have a semidominant pattern of inheritance. Thus, although all five alleles tested have loss-of-function behavior with respect to $\beta$-lobe morphology at the midline, three of them $(\Delta 83, \Delta 50$, and, to a lesser extent, $P[E P] 3517)$ have gainof-function properties with respect to $\alpha$ - and $\beta$-lobe formation and projection.

\section{A deficiency chromosome reveals regulators of $\mathrm{MB}$ maturation during metamorphosis}

As part of our efforts to map the $\beta$-lobe midline-crossing phenotype, we placed $\Delta 83$ in combination with $D f(3 R) b y 62$, the only available cytologically visible deletion in the $d f m r 1$ region. Onethird of $\Delta 83 / D f(3 R)$ by 62 MBs showed accessory phenotypes, in keeping with the semidominant, gain-of-function effect of $\Delta 83$ described above. However, only $8 \%$ exhibited the $\beta$-lobe midline-crossing phenotype, and it was only mild or moderate in severity $(n=39)$. On closer examination of the FasII-labeled MBs in $\Delta 83 / D f(3 R) b y 62$ pharate adults, we recognized that the $\alpha$ and $\beta$ lobes appeared very immature, resembling those seen in wild-type brains at earlier stages of metamorphosis (Fig. $5 A-C$ ). In many cases, the lobes appeared younger than those of pupae whose $\beta$-lobe fibers were just approaching the midline. Similar results were seen in $\Delta 113$ / 
$D f(3 R) b y 62$ and $P[E P] 3517 / D f(3 R) b y 62$ pharate adults (data not shown). Hence, this new phenotype precludes the use of $D f(3 R) b y 62$ for mapping $\mathrm{MB}$ phenotypes. Nonetheless, as explained below, it has revealed novel information about the genetic basis of $\mathrm{MB}$ maturation during metamorphosis.

The $\mathrm{MB} \alpha / \beta$ immaturity phenotype is characterized by abnormally thin $\alpha$ and $\beta$ lobes that are very irregular along their lengths (Fig. 5A-C), whereas the $\gamma$ lobes appear normal. Because lobe thickness and contour vary somewhat in mature wild-type brains, and because the phenotypes of $\Delta 83 / D f(3 R) b y 62$ brains were variable, we coded a large number of $M B$ images from different genotypes and, thus blinded, developed a categorical maturity scoring scheme (see Materials and Methods): WNL, moderate, and severe (Fig. 5A-C). Subsequent scoring was done blind to genotype. Genetic features of the $\alpha / \beta$ immaturity phenotype were revealed by comparison of $D f / \Delta 83$ and $D f /$ Balancer siblings generated in two independent experiments by somewhat different mating schemes (Fig. 6; for details, see legend). Figure 6, $A$ and $B$, depicts the data graphically and demonstrates a dominant effect of $D f(3 R) b y 62$. In each experiment, $80-90 \%$ of both $\Delta 83$ / $D f(3 R)$ by 62 and $D f(3 R)$ by $62 /$ Balancer brains showed $\alpha / \beta$-lobe immaturity. In contrast, all $\mathrm{MBs}$ of $\Delta 83 /$ Balancer siblings were WNL (Fig. 6B). In a third experiment, we examined the $D f(3 R)$ by $62 /+$ progeny of $D f(3 R)$ by $62 / T M 6 C$ and OreRC parents (Fig. 6C). Again, $>90 \%$ of the MBs of deficiency heterozygotes were immature, confirming the dominant effect of the deficiency.

A comparison of $D f(3 R) b y 62$ over a $d f m r 1^{+}$chromosome (balancer or OreRC) with $D f(3 R)$ by 62 over the $d f m r 1$ allele $\Delta 83$ reveals a clear difference in the severity profiles of $\mathrm{MB}$ immaturity. For $D f /+$, in three independent experiments scored blind, the majority of samples showed moderate immaturity phenotypes. In contrast, when the deficiency is paired with a $d f m r 1$ mutation, $40-50 \%$ of the brains show severe MB immaturity. Thus, although the effect of $D f(3 R) b y 62$ is dominant, the severity of the immaturity phenotype is enhanced by $\Delta 83$, demonstrating genetic interaction between $d f m r 1$ and the deficiency chromosome. This synergistic interaction is likely to involve one or more loci in the deficiency interval flanking $d f m r 1$, but other sites on the third chromosome may participate as well.

The MB immaturity phenotype could result from either arrest or delay of $\alpha$ - and $\beta$-lobe development. To distinguish between these two mechanistic possibilities, we compared MB development in $\Delta 83 / D f(3 R)$ by 62 and wild-type brains at successive times during the first half of metamorphosis (Fig. 5D-I). MB lobe development of $\Delta 83 / D f(3 R)$ by 62 brains appears immature beginning at $\mathrm{HE}+18 \mathrm{hr}$ (Fig. 5E), and the disparity with the wild type gets progressively worse over time thereafter (Fig. $5 F-I$ ). However, there is a progressive, albeit very slow, increase in lobe maturation in the $\Delta 83 / D f(3 R)$ by 62 brains, indicating that the developmental defect is one of delay and not arrest. Taken together, the data suggest a role for $d f m r 1$ in the overall rate of $\alpha / \beta$-lobe maturation.

\section{Discussion \\ dFMRP limits neurite extension in a learning and memory brain center}

We have demonstrated that $d f m r 1$ mutations cause a strongly penetrant neuronal overextension phenotype, in a highly plastic brain region well known for its role in multimodal sensory integration, olfactory associative learning, and visual context generalization (Zars, 2000; Roman and Davis, 2001). The $\beta$-lobe midline-crossing phenotype has recessive, loss-of-function characteristics and arises during the de novo differentiation of $\alpha / \beta$ neurons during metamorphic development of the MBs. Neuronal excess is a recurring theme in the fmrl mutant phenotypes of both flies (Zhang et al., 2001; Dockendorff et al., 2002; Morales et al., 2002; Lee et al., 2003; this study) and mammals (Comery et al., 1997; Irwin et al., 2001), although some neuron types show reduced axon extension (Morales et al., 2002). From an evolutionary perspective, midline fusion of $\mathrm{MB}$ lobes represents an atavistic change: a reversion to a more primitive form (Strausfeld et al., 1998).

Despite the simultaneous process outgrowth of newly born $\alpha / \beta$ neurons and regenerating $\gamma$ neurons, the $d$ fmrl midlinecrossing phenotype is restricted to the $\beta$ lobes, with regrowing $\gamma$ lobe axons respecting the brain midline. This differential sensitivity of $\gamma$ and $\alpha / \beta$ neurons to $d f m r 1$ mutations parallels their distinct cognitive functions. $\gamma$ lobes are required for short-term olfactory memory formation (Zars et al., 2000), whereas shortterm memory is not affected by lack of $\alpha$ and $\beta$ lobes (Pascual and Préat, 2001). Rather, $\alpha / \beta$ lobes mediate olfactory memory retrieval (McGuire et al., 2001) and long-term memory formation (Pascual and Préat, 2001). On the basis of these studies and others (Heisenberg, 2003) linking MB structure with cognitive functions, we predict that $d f m r 1$ mutants will show memory phenotypes that help clarify the specific function of $\alpha / \beta$ neurons.

The midline-crossing defect of $d f m r 1$ mutant MBs implies either the lack of a midline repulsive signal or, alternatively, a failure by $\beta$-lobe axons to sense, recognize, or respond to that "stop" signal. Other mutant conditions that cause $\mathrm{MB}$ axon overextension across the midline provide clues to the underlying mechanism(s). The memory mutant linotte (lio) (Dura et al., 1993) also has a recessive, highly penetrant $\beta$-lobe midlinecrossing phenotype that is sensitive to genetic background and sometimes accompanied by missing $\alpha$ lobes (Moreau-Fauvarque et al., 1998; Simon et al., 1998). lio is expressed in the developing MBs, especially the $\alpha$ and $\beta$ lobes (Moreau-Fauvarque et al., 1998), as well as in a transient midline glial "ring" whose structure it regulates (Simon et al., 1998). lio is probably identical to the atypical receptor tyrosine kinase-encoding derailed gene (Moreau-Fauvarque et al., 2002) (but see Bolwig et al., 1995), which mediates repulsive signaling via the ligand Wnt5 in the embryonic nerve cord, preventing midline crossing by developing axons (Bonkowsky et al., 1999). Mutations of castor, which encodes a transcription factor expressed in a subset of CNS progenitor cells, also cause $\beta$-lobe midline crossing and interact with linotte mutations (Hitier et al., 2001). Overexpression of the actin-binding protein Ciboulot induces $\beta$-lobe midline crossing (Boquet et al., 2000). The involvement of regulators of transcription (Castor), translation (dFMRP), cell surface signaling (Linotte/Derailed), and the actin cytoskeleton (Ciboulot) highlights the complex pathway controlling MB lobe morphogenesis. Translational repression of ciboulot by dFMRP would explain the observed phenotypes. Finally, mutations in the dFMRP interactor CYFIP cause midline-crossing defects in the embryonic CNS (Schenck et al., 2003). By analogy with mechanisms controlling axon behavior there, dFMRP may regulate Slit-Roundabout signaling (Guthrie, 2001).

\section{Genetic complexities of the $d f m r 1$ locus: parallels to mammalian Fmr1}

Three types of genetic complexity associated with $d f m r 1$ provide challenges to understanding its biology, as well as opportunities to discover loci involved in its function. First, the recessive $d f m r 1$ overextension phenotype is very sensitive to genetic background, such that related third-chromosome balancers enhance the phe- 


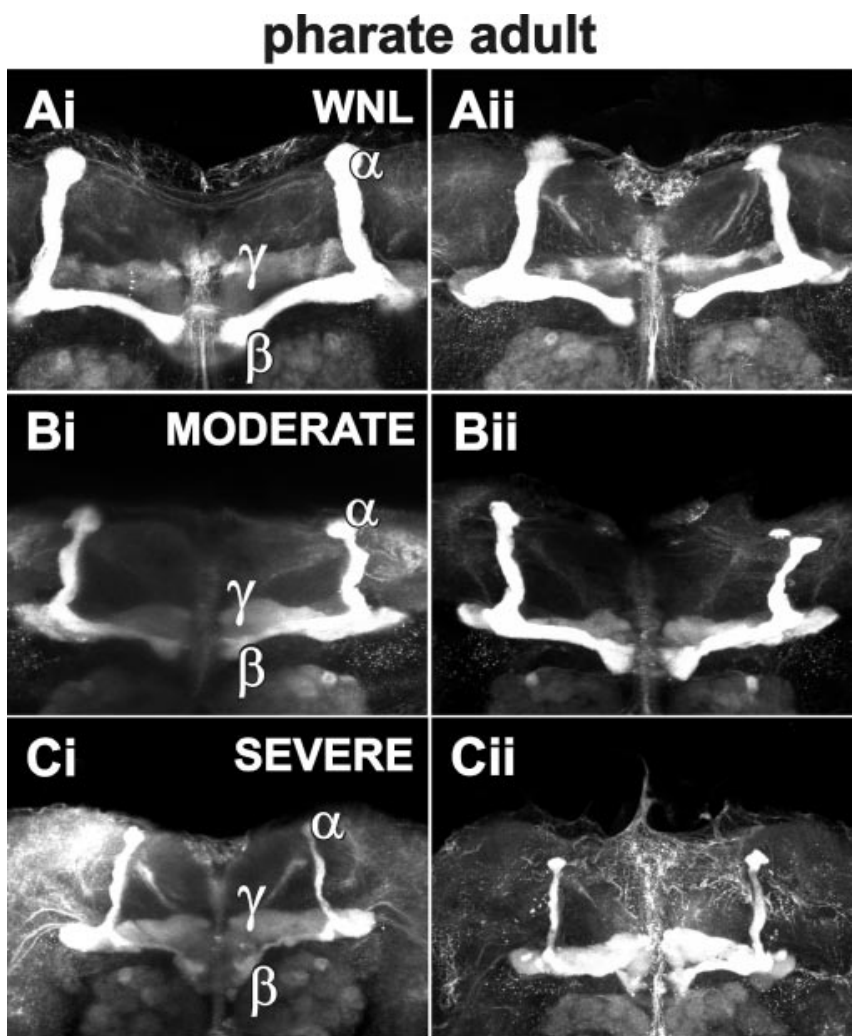

wildtype

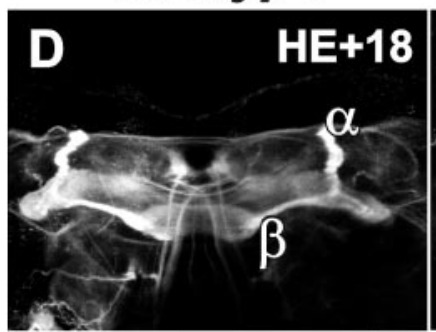

$\Delta 83 / D f(3 R) b y 62$
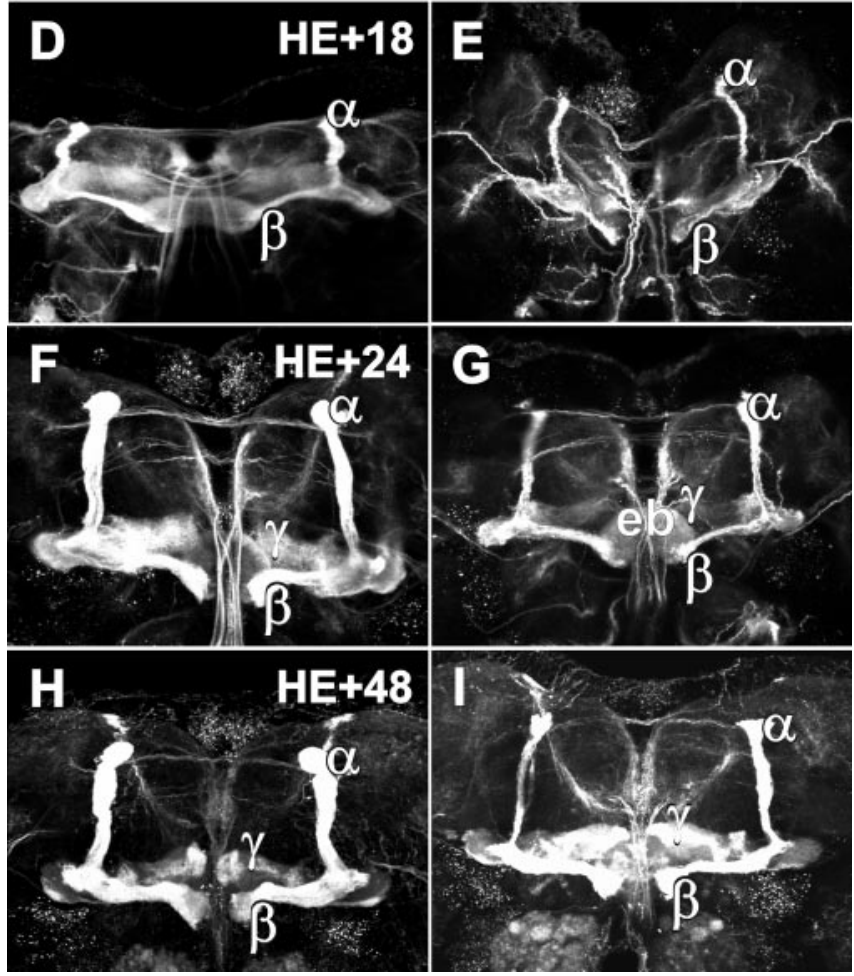

Figure 5. The $M B \alpha / \beta$-lobe immaturity phenotype associated with $D f(3 R)$ by 62 : phenotypic variation and development. Projections of sequential optical sections through MB lobe regions of Fasll-immunostained brains are shown. Frontal views; dorsal is at the top. $A-C$, Pharate adult progeny siblings from the mating of $\Delta 83 / T M 6 B$ to $D f(3 R)$ by62/TM6C. $\alpha / \beta$ maturity was scored blind and classified as WNL, moderately immature (moderate), or severely immature (severe). Two representative examples of each are shown. Ai, Aii, WNL $(\Delta 83 / T M 6 C)$. There is some variation in the thickness and contour of normal $\alpha / \beta$ lobes (also see Fig. 1 A). Bi, Bii, Moderate
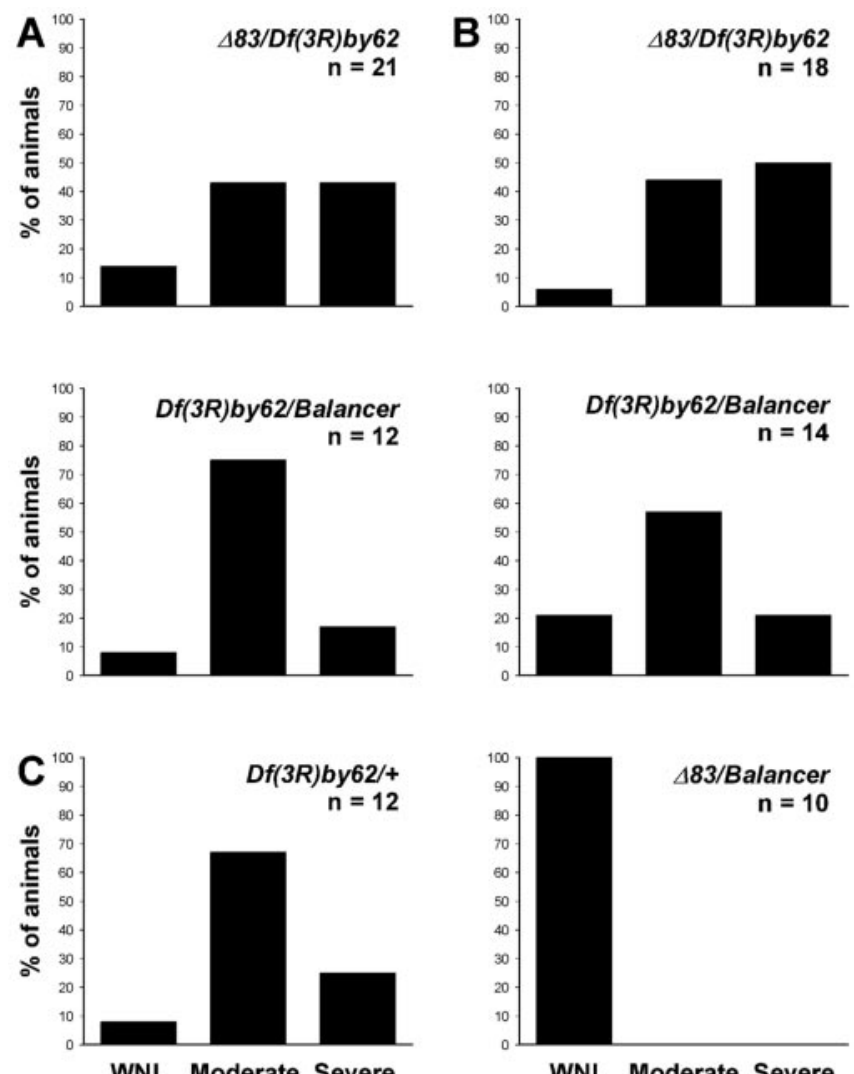

WNL Moderate Severe

Figure 6. The $D f(3 R)$ by62-associated $\alpha / \beta$ immaturity phenotype is dominant and enhanced by dfmr1 mutations. $A-C$, Three independent experiments in which Fasll-labeled pharate adult brains were scored for $\alpha / \beta$-lobe maturity as in Figure 5 . All samples were scored blind with respect to genotype. $A$, Progeny siblings from the mating of $\triangle 83 / T M 6 B$ to Df(3R)by62/TM1. In Df(3R)by62/Balancer [Df(3R)by62/TM6B] brains, most of the $\alpha / \beta$ lobes were outside the normal maturity range. In $\Delta 83 / D f(3 R) b y 62$ siblings, the immaturity phenotypes were shifted toward greater severity. $B$, Genotypes associated with the mating of $201 Y$ UAS-GFP; $\triangle 83 / T M 6 B$ to Df(3R)by62/TM6C. $\Delta 83 / D f(3 R)$ by62, Progeny siblings. Df(3R)by62/Balancer includes $D f(3 R)$ by62/TM6B progeny siblings as well as the parental genotype $D f(3 R)$ by62/ TM6C. Once again, the presence of $\Delta 83$ enhances the phenotypic severity of $\alpha / \beta$-lobe immaturity associated with $D f(3 R) b y 62$. In contrast, the $\alpha / \beta$ lobes of $\Delta 83 /$ Balancer ( $\triangle 83 / T M 6 C$ ) siblings are $100 \%$ within the normal range. $C, D f(3 R) b y 62 /+$ progeny from the cross of Df(3R)by62/TM6C to the wild-type OreRC strain. Less than $10 \%$ of brains showed $\alpha / \beta$ maturity in the normal range, confirming the dominant effect of $D f(3 R) b y 62$.

notype to varying degrees. The very features that make balancers such powerful tools, breakpoints that prevent recombination and markers that can be followed through successive generations (Greenspan, 1997), may act in trans as modifiers of mutations under study. While the source of genetic background variation is different in murine inbred strains, the phenomenon of

\footnotetext{
[ $\Delta 83 / D f(3 R) b y 62]$. Note the apparent abrupt changes in lobe diameter, especially of the $\alpha$ lobes. $C i$, Cii, Severe $[\Delta 83 / D f(3 R) b y 62]$. The lobes are very thin and wiggly, reminiscent of wild-type early pupal $\alpha / \beta$-lobe development (also see Fig. 4). $D-I, \alpha / \beta$-lobe development during metamorphosis. Times indicated are hours after $\mathrm{HE}$. Pairs of images compare wild type (201Y UAS-GFP/+) in the left column $(D, F, H)$ with $\triangle 83 / D f(3 R) b y 62$ in the right column $(E, G$, $I$ ) at the same developmental stage. $D, E, H E+18 \mathrm{hr}$. The $\alpha / \beta$ lobes in the $\Delta 83 / D f$ animals appear thinner than comparably aged normal brains. $F, G, H E+24 \mathrm{hr} . \alpha / \beta$-lobe development is delayed in $\Delta 83 / D f$ animals; on the basis of their thickness, the lobes are similar to those of a normal brain $6-8 \mathrm{hr}$ younger (also see Fig. 3). $\mathrm{H}, \mathrm{I}, \mathrm{HE}+48 \mathrm{hr}$. At the midpupal stage, $\Delta 83 / \mathrm{Df}$ brains show even more delay in $\alpha / \beta$-lobe development. On the basis of their thin diameter (especially the left side) and excessive contour variation (on the right side), the $\alpha / \beta$ lobes of this brain are $>24 \mathrm{hr}$ delayed in maturation.
} 
background-dependent phenotype modification is common and, as in the case of Fmr1, may be dramatic. The size of particular terminal fields within the hippocampus is significantly reduced, and associated with poor spatial learning, in mice whose Fmr1 mutation was on a C57Bl/6 background (Mineur et al., 2002), whereas that structure was significantly enlarged when the same mutation was crossed onto an FVB background (Ivanco and Greenough, 2002). Similarly, MB phenotypes due to mutations of mushroom bodies miniature vary greatly depending on genetic background (deBelle and Heisenberg, 1996).

Second, the $d f m r l$ accessory phenotypes causing misdirection or absence of $\alpha$ and $\beta$ lobes, presumably because of pathfinding errors, are semidominant, incompletely penetrant, and associated with a subset of $d f m r 1$ mutations. The phenotypic constellation of $\beta$-lobe midline crossing plus $\alpha / \beta$ misdirection has been reported for mutants of two other genes, linotte, which is quite similar to $d f m r 1$ in its MB phenotype (Moreau-Fauvarque et al., 1998), and alpha-lobes-absent, which shows highly penetrant $\alpha / \beta$-lobe misdirection and infrequent $\beta$-lobe midline crossing (Pascual and Préat, 2001). Thus, the accessory phenotypes of $d f m r 1$ cannot be easily dismissed. Nonetheless, their allele specificity and semidominant nature are perplexing and suggest two alternative explanations. All of the imprecise excision alleles fail to produce a protein product detectable by a monoclonal antibody (Wan et al., 2000; Zhang et al., 2001; Dockendorff et al., 2002; Morales et al., 2002) that recognizes an epitope in the N-terminal $40 \%$ of the protein (T. Jongens, personal communication). However, the alleles that produce accessory phenotypes, the $P[E P] 3517$ insertion allele, and the two imprecise excision alleles with the least loss of $d f m r 1$ coding sequence $(\Delta 83$ and $\Delta 50)$ might be capable of directing expression of an altered $d f m r 1$ transcript or protein, with gain-of-function properties and undetectable by the monoclonal antibody. The rescue of accessory phenotypes in the precise-excision line is consistent with this model. Moreover, there is a precedent for gain-of-function Fmr1 phenotypes in mammals. Elevated levels of Fmr1 RNA associated with fragile-X premutation alleles cause premature ovarian failure in females and a neurodegenerative disorder in older males (Oostra and Willemsen, 2003). Alternatively, if all the excision alleles are truly nulls, then $\Delta 83, \Delta 50$, and $P[E P] 3517$ chromosomes may share a linked allelic variant that acts alone, or in concert with $d f m r 1$ mutations, to induce $\alpha / \beta$ pathfinding defects.

Third, a large chromosomal deficiency that flanks $d f m r 1$, $D f(3 R)$ by 62 , has a dominant effect on the $\mathrm{MB} \alpha / \beta$ lobes, causing developmental delay that is enhanced by $d f m r 1$ mutations. The genetic interaction between $d f m r 1$ and the deficiency chromosome indicates that $d f m r 1$ participates in a second aspect of $\alpha / \beta$ development, boosting the rate of lobe maturation during metamorphosis. It also makes loci in the vicinity of $d f m r 1$ (85D10-11 through 85F8-11) candidate target genes of dFMRP. Several mechanisms could explain the apparent inhibition of $\beta$-lobe midline crossing in most $d f m r 1 / D f(3 R)$ by 62 animals: (1) lobe development is so compromised that fibers do not progress far enough to cross; (2) a critical period "permissive" for midline crossing is missed because of developmental delay; or (3) phenotypic suppression is caused by an interacting dosage-sensitive locus.

\section{D. melanogaster as a model for fragile $\mathrm{X}$ syndrome}

The Drosophila genetic model system is valuable for studying molecular pathophysiology of human disease (Bonini, 2000; Lasko, 2002; Driscoll and Gerstbrein, 2003). Perhaps most exciting is its use to identify novel therapeutic strategies for neurolog- ical disorders with few treatment options (Warrick et al., 1999; Kazantsev et al., 2002). The circadian rhythm and neuronal morphology phenotypes of $d f m r 1$ mutants (Zhang et al., 2001; Dockendorff et al., 2002; Inoue et al., 2002; Morales et al., 2002; Lee et al., 2003; this study) are reminiscent of human fragile X sleep disorders (Gould et al., 2000) and cortical neuropathology (Irwin et al., 2001), respectively. Genetic and biochemical approaches in Drosophila have identified two dFMRP targets, a MAP1B homolog (Zhang et al., 2001) and Rac1 (Lee et al., 2003; Schenck et al., 2003). In addition, experiments in Drosophila have been central to demonstrating the involvement of small interfering RNA and micro RNA in the translational control mechanism of FMRP (Caudy et al., 2002; Ishizuka et al., 2002; Schenck et al., 2003; Jin et al., 2004). The sensitivity of $d f m r 1$-regulated MB structure to genetic interactions will allow screening for dFMRP targets and interacting proteins relevant to cognition and other behaviors.

The $d$ fmr 1 model of fragile $\mathrm{X}$ syndrome should also be viewed in the wider context of phylogenetic conservation of genes controlling cognition. Fundamental molecular mechanisms of learning and memory are shared between vertebrates and invertebrates (Mayford and Kandel, 1999). Of the $\sim 300$ molecularly identified human mental retardation genes, $87 \%$ have a homolog, and $76 \%$ have a single-candidate functional ortholog in Drosophila (Inlow and Restifo, 2004). Some of these Drosophila genes have already revealed neurological phenotypes, including learning and memory defects (Inlow and Restifo, 2004, and references therein).

Drosophila MBs manifest not only developmental reorganization (Technau and Heisenberg, 1982; Lee et al., 1999), but also experience-dependent plasticity (Technau, 1984; Heisenberg et al., 1995; Barth and Heisenberg, 1997). Hence, MB phenotypes in Drosophila mental retardation gene mutants are of particular interest. Drosophila Lissencephaly-1 was the first of these to be shown to regulate MB neuronal structure (Liu et al., 2000). Our demonstration of $d f m r 1 \mathrm{MB}$ defects suggests that others are likely to follow as additional mental retardation genes are studied in Drosophila.

\section{References}

Antar LN, Bassell GJ (2003) Sunrise at the synapse: the FMRP mRNP shaping the synaptic interface. Neuron 37:555-558.

Bainbridge SP, Bownes M (1981) Staging the metamorphosis of Drosophila melanogaster. J Embryol Exp Morphol 66:57-80.

Barth M, Heisenberg M (1997) Vision affects mushroom bodies and central complex in Drosophila melanogaster. Learn Mem 4:219-229.

Bennetto L, Pennington BF (2002) Neuropsychology. In: Fragile X syndrome: diagnosis, treatment, and research, Ed 3 (Hagermann PJ, ed), pp 206-250. Baltimore: Johns Hopkins UP.

Bolwig GM, Del Vecchio M, Hannon G, Tully T (1995) Molecular cloning of linotte in Drosophila: a novel gene that functions in adults during associative learning. Neuron 15:829-842.

Bonini NM (2000) Drosophila as a genetic tool to define vertebrate pathway players. Methods Mol Biol 136:7-14.

Bonkowsky JL, Yoshikawa S, O'Keefe DD, Scully AL, Thomas JB (1999) Axon routing across the midline controlled by the Drosophila Derailed receptor. Nature 402:540-544.

Boquet I, Boujemaa R, Carlier M-F, Préat T (2000) Ciboulot regulated actin assembly during Drosophila brain metamorphosis. Cell 102:797-808.

Brand AH, Dormand E-L (1995) The GAL4 system as a tool for unravelling the mysteries of the Drosophila nervous system. Curr Opin Neurobiol 5:572-578.

Braun K, Segal M (2000) FMRP involvement in formation of synapses among cultured hippocampal neurons. Cereb Cortex 10:1045-1052.

Brown V, Jin P, Ceman S, Darnell JC, O’Donnell WT, Tenenbaum SA, Jin X, Feng Y, Wilkinson KD, Keene JD, Darnell RB, Warren ST (2001) Microarray identification of FMRP-associated brain mRNAs and altered mRNA translational profiles in fragile X syndrome. Cell 107:477-487. 
Budnik V, Martin-Morris L, White K (1986) Perturbed pattern of catecholamine-containing neurons in mutant Drosophila deficient in the enzyme dopa decarboxylase. J Neurosci 6:3682-3691.

Caudy AA, Myers M, Hannon GJ, Hammond SM (2002) Fragile X-related protein and VIG associate with the RNA interference machinery. Genes Dev 16:2491-2496.

Comery TA, Harris JB, Willems PJ, Oostra BA, Irwin SA, Weiler IJ, Greenough WT (1997) Abnormal dendritic spines in fragile X knockout mice: maturation and pruning deficits. Proc Natl Acad Sci USA 94:5401-5404.

Crittenden JR, Skoulakis EMC, Han K-A, Kalderon D, Davis RL (1998) Tripartite mushroom body architecture revealed by antigenic markers. Learn Mem 5:38-51.

Cubitt AB, Heimar R, Adams SR, Boyd AE, Gross LA, Tsien RY (1995) Understanding, improving and using green fluorescent proteins. Trends Biochem Sci 20:448-455.

Darnell JC, Jensen KB, Jin P, Brown V, Warren ST, Darnell RB (2001) Fragile X mental retardation protein targets $\mathrm{G}$ quartet mRNAs important for neuronal function. Cell 107:489-499.

deBelle JS, Heisenberg M (1996) Expression of Drosophila mushroom body mutations in alternative genetic backgrounds: a case study of the mushroom body miniature gene ( $\mathrm{mbm}$ ). Proc Natl Acad Sci USA 93:9875-9880.

Devys D, Lutz Y, Rouyer N, Bellocq JP, Mandel JL (1993) The FMR-1 protein is cytoplasmic, most abundant in neurons and appears normal in carriers of a fragile X premutation. Nat Genet 4:335-340.

Dobkin C, Rabe A, Dumas R, El Idrissi A, Haubenstock H, Brown WT (2000) Fmr1 knockout mouse has a distinctive strain-specific learning impairment. Neuroscience 100:423-429.

Dockendorff TC, Su HS, McBride SM, Yang Z, Choi CH, Siwicki KK, Sehgal A, Jongens TA (2002) Drosophila lacking dfmrl activity show defects in circadian output and fail to maintain courtship interest. Neuron 34:973-984.

Driscoll M, Gerstbrein B (2003) Dying for a cause: invertebrate genetics takes on human neurodegeneration. Nat Rev Genet 4:181-194.

Dura J-M, Préat T, Tully T (1993) Identification of linotte, a new gene affecting learning and memory in Drosophila melanogaster. J Neurogenet 9:1-14.

Dutch-Belgian Fragile X Consortium (1994) Fmr1 knockout mice: a model to study fragile X mental retardation. Cell 78:23-33.

Elgin SR, Miller DW (1978) Mass rearing of flies and mass production and harvesting of eggs. In: The genetics and biology of Drosophila (Wright TRF, ed), pp 112-121. New York: Academic.

Feng Y, Gutekunst CA, Eberhart DE, Yi H, Warren ST, Hersch SM (1997) Fragile X mental retardation protein: nucleocytoplasmic shuttling and association with somatodendritic ribosomes. J Neurosci 17:1539-1547.

Galvez R, Gopal AR, Greenough WT (2003) Somatosensory cortical barrel dendritic abnormalities in a mouse model of the fragile $\mathrm{X}$ mental retardation syndrome. Brain Res 971:83-89.

Gould EL, Loesch DZ, Martin M, Hagerman RJ, Armstrong SM, Huggins RM (2000) Melatonin profiles and sleep characteristics in boys with fragile $\mathrm{X}$ syndrome: a preliminary study. Am J Med Genet 95:307-315.

Greenough WT, Klintsova AY, Irwin SA, Galvez R, Bates KE, Weiler IJ (2001) Synaptic regulation of protein synthesis and the fragile $\mathrm{X}$ protein. Proc Natl Acad Sci USA 98:7101-7106.

Greenspan RJ (1997) Fly pushing: the theory and practice of Drosophila genetics. Cold Spring Harbor, NY: Cold Spring Harbor Laboratory.

Guthrie S (2001) Axon guidance: Robos make the rules. Curr Biol 11:R300-R303.

Hagerman RJ (2002) The physical and behavioral phenotype. In: Fragile X syndrome: diagnosis, treatment, and research, Ed 3 (Hagermann PJ, ed), pp 3-109. Baltimore: Johns Hopkins UP.

Heisenberg M (2003) Mushroom body memoir: from maps to models. Nat Rev Neurosci 4:266-275.

Heisenberg M, Heusipp M, Wanke C (1995) Structural plasticity in the Drosophila brain. J Neurosci 15:1951-1960.

Hinton VJ, Brown WT, Wisniewski K, Rudelli RD (1991) Analysis of neocortex in three males with the fragile X syndrome. Am J Med Genet 41:289-294.

Hitier R, Chaminade M, Préat T (2001) The Drosophila castor gene is involved in postembryonic brain development. Mech Dev 103:3-11.

Huber KM, Gallagher SM, Warren ST, Bear MF (2002) Altered synaptic plasticity in a mouse model of fragile $\mathrm{X}$ mental retardation. Proc Natl Acad Sci USA 99:7746-7750.

Inlow JK, Restifo LL (2004) Molecular and comparative genetics of mental retardation. Genetics 166:835-881.

Inoue S, Shimoda M, Nishinokubi I, Siomi MC, Okamura M, Nakamura A, Kobayashi S, Ishida N, Siomi H (2002) A role for the Drosophila fragile $\mathrm{X}$-related gene in circadian output. Curr Biol 12:1331-1335.

Irwin SA, Swain RA, Christmon CA, Chakravarti A, Weiler IJ, Greenough WT (2000) Evidence for altered Fragile-X mental retardation protein expression in response to behavioral stimulation. Neurobiol Learn Mem 73:87-93.

Irwin SA, Patel B, Idupulapati M, Harris JB, Crisostomo RA, Larsen BP, Kooy F, Willems PJ, Cras P, Kozlowski PB, Swain RA, Weiler IJ, Greenough WT (2001) Abnormal dendritic spine characteristics in the temporal and visual cortices of patients with fragile-X syndrome: a quantitative examination. Am J Med Genet 98:161-167.

Irwin SA, Idupulapati M, Gilbert ME, Harris JB, Chakravarti AB, Rogers EJ, Crisostomo RA, Larsen BP, Mehta A, Alcantara CJ, Patel B, Swain RA, Weiler IJ, Oostra BA, Greenough WT (2002) Dendritic spine and dendritic field characteristics of layer $\mathrm{V}$ pyramidal neurons in the visual cortex of fragile-X knockout mice. Am J Med Genet 111:140-146.

Ishizuka A, Siomi MC, Siomi H (2002) A Drosophila fragile X protein interacts with components of RNAi and ribosomal proteins. Genes Dev 16:2497-2508.

Ito K, Sass H, Urban J, Hofbauer A, Schneuwly S (1997) GAL4-responsive UAS-tau as a tool for studying the anatomy and development of the Drosophila central nervous system. Cell Tissue Res 290:1-10.

Ivanco TL, Greenough WT (2002) Altered mossy fiber distributions in adult Fmr1 (FVB) knockout mice. Hippocampus 12:47-54.

Jin P, Warren ST (2000) Understanding the molecular basis of fragile X syndrome. Hum Mol Genet 9:901-908.

Jin P, Warren ST (2003) New insights into fragile X syndrome: from molecules to neurobehaviors. Trends Biochem Sci 28:152-158.

Jin P, Zarnescu DC, Ceman S, Nakamoto M, Mowrey J, Jongens TA, Nelson DL, Moses K, Warren ST (2004) Biochemical and genetic interaction between the fragile $\mathrm{X}$ mental retardation protein and the microRNA pathway. Nat Neurosci 7:113-117.

Kates WR, Folley BS, Lanham DC, Capone GT, Kaufmann WE (2002) Cerebral growth in Fragile X syndrome: review and comparison with Down syndrome. Microsc Res Tech 57:159-167.

Kaytor MD, Orr HT (2001) RNA targets of the fragile X protein. Cell 107:555-557.

Kazantsev A, Walker HA, Slepko N, Bear JE, Preisinger E, Steffan JS, Zhu YZ, Gertler FB, Housman DE, Marsh JL, Thompson LM (2002) A bivalent Huntingtin binding peptide suppresses polyglutamine aggregation and pathogenesis in Drosophila. Nat Genet 30:367-376.

Kirkpatrick LL, McIlwain KA, Nelson DL (2001) Comparative genomic sequence analysis of the FXR gene family: FMR1, FXR1, and FXR2. Genomics 78:169-177.

Kooy RF (2003) Of mice and the fragile X syndrome. Trends Genet 19:148-154.

Kraft R, Levine RB, Restifo LL (1998) The steroid hormone 20hydroxyecdysone enhances neurite growth of Drosophila mushroom body neurons isolated during metamorphosis. J Neurosci 18:8886-8899.

Laggerbauer B, Ostareck D, Keidel EM, Ostareck-Lederer A, Fischer U (2001) Evidence that fragile X mental retardation protein is a negative regulator of translation. Hum Mol Genet 10:329-338.

Lasko P (2002) Diabetic flies? Using Drosophila melanogaster to understand the causes of monogenic and genetically complex diseases. Clin Genet 62:358-367.

Lee A, Li W, Xu K, Bogert BA, Su K, Gao FB (2003) Control of dendritic development by the Drosophila fragile $X$-related gene involves the small GTPase Rac1. Development 130:5543-5552.

Lee T, Luo L (1999) Mosaic analysis with a repressible cell marker for studies of gene function in neuronal morphogenesis. Neuron 22:451-461.

Lee T, Lee A, Luo L (1999) Development of the Drosophila mushroom bodies: sequential generation of three distinct types of neurons from a neuroblast. Development 126:4065-4076.

Li Z, Zhang Y, Ku L, Wilkinson KD, Warren ST, Feng Y (2001) The fragile X mental retardation protein inhibits translation via interacting with mRNA. Nucleic Acids Res 29:2276-2283.

Liu Z, Steward R, Luo L (2000) Drosophila Lis1 is required for neuroblast 
proliferation, dendritic elaboration and axonal transport. Nat Cell Biol 2:776-783

Mayford M, Kandel ER (1999) Genetic approaches to memory storage. Trends Genet 15:463-470.

Mazroui R, Huot ME, Tremblay S, Filion C, Labelle Y, Khandjian EW (2002) Trapping of messenger RNA by Fragile X Mental Retardation Protein into cytoplasmic granules induces translation repression. Hum Mol Genet 11:3007-3017.

McGuire SE, Le PT, Davis RL (2001) The role of Drosophila mushroom body signaling in olfactory memory. Science 293:1330-1333.

Mineur YS, Sluyter F, de Wit S, Oostra BA, Crusio WE (2002) Behavioral and neuroanatomical characterization of the Fmrl knockout mouse. Hippocampus 12:39-46.

Morales J, Hiesinger PR, Schroeder AJ, Kume K, Verstreken P, Jackson FR, Nelson DL, Hassan BA (2002) Drosophila fragile X protein, DFXR, regulates neuronal morphology and function in the brain. Neuron 34:961-972.

Moreau-Fauvarque C, Taillebourg E, Boissoneau E, Mesnard J, Dura J-M (1998) The receptor tyrosine kinase gene linotte is required for neuronal pathway selection in the Drosophila mushroom bodies. Mech Dev 78:47-61.

Moreau-Fauvarque C, Taillebourg E, Préat T, Dura J-M (2002) Mutation of linotte causes behavioral defects independent of pigeon in Drosophila. NeuroReport 13:2309-2312.

Nimchinsky EA, Oberlander AM, Svoboda K (2001) Abnormal development of dendritic spines in FMR1 knock-out mice. J Neurosci 21:5139-5146.

O'Donnell WT, Warren ST (2002) A decade of molecular studies of fragile X syndrome. Annu Rev Neurosci 25:315-338.

Oostra BA, Willemsen R (2003) A fragile balance: FMR1 expression levels. Hum Mol Genet 12:R249-R257.

Paradee W, Melikian HE, Rasmussen DL, Kenneson A, Conn PJ, Warren ST (1999) Fragile X mouse: strain effects of knockout phenotype and evidence suggesting deficient amygdala function. Neuroscience 94:185-192.

Pascual A, Préat T (2001) Localization of long-term memory within the Drosophila mushroom body. Science 294:1115-1117.

Rein K, Zockler M, Mader M, Grubel C, Heisenberg M (2002) The Drosophila standard brain. Curr Biol 12:227-231.

Restifo LL, Merrill VKL (1994) Two Drosophila regulatory genes, Deformed and the Broad-Complex, share common functions in development of adult CNS, head, and salivary glands. Dev Biol 162:465-485.

Restifo LL, White K (1991) Mutations in a steroid hormone-regulated gene disrupt the metamorphosis of the central nervous system in Drosophila. Dev Biol 148:174-194.

Robertson HM, Preston CR, Phillis RW, Johnson-Schlitz DM, Benz WK, Engels WR (1988) A stable genomic source of $P$ element transposase in Drosophila melanogaster. Genetics 118:461-470.

Roman G, Davis RL (2001) Molecular biology and anatomy of Drosophila olfactory associative learning. BioEssays 23:571-581.

Rudelli RD, Brown WT, Wisniewski K, Jenkins EC, Laure-Kamionowska M, Connell F, Wisniewski HM (1985) Adult fragile X syndrome: cliniconeuropathologic findings. Acta Neuropathol (Berl) 67:289-295.

Schaeffer C, Bardoni B, Mandel JL, Ehresmann B, Ehresmann C, Moine H (2001) The fragile X mental retardation protein binds specifically to its mRNA via a purine quartet motif. EMBO J 20:4803-4813.
Schenck A, Bardoni B, Langmann C, Harden N, Mandel J-L, Giangrande A (2003) CYFIP/Sra-1 controls neuronal connectivity in Drosophila and links the Racl GTPase pathway to the fragile X protein. Neuron 38:887-898.

Sherman S (2002) Epidemiology. In: Fragile X syndrome: diagnosis, treatment, and research, Ed 3 (Hagermann PJ, ed), pp 136-168. Baltimore: Johns Hopkins UP.

Simon A, Boquet I, Synguélakis M, Préat T (1998) The Drosophila putative kinase Linotte (Derailed) prevents central brain axons from converging on a newly described interhemispheric ring. Mech Dev 76:45-55.

Siomi MC, Higashijima K, Ishizuka A, Siomi H (2002) Casein kinase II phosphorylates the fragile $\mathrm{X}$ mental retardation protein and modulates its biological properties. Mol Cell Biol 22:8438-8447.

Strausfeld NJ, Hansen L, Li Y, Gomez RS, Ito K (1998) Evolution, discovery, and interpretations of arthropod mushroom bodies. Learn Mem 5:11-37.

Strausfeld NJ, Sinakevitch I, Vilinsky I (2003) The mushroom bodies of Drosophila melanogaster: an immunocytological and Golgi study of Kenyon cell organization in the calyces and lobes. Microsc Res Tech 62:151-169.

Technau GM (1984) Fiber number in the mushroom bodies of adult Drosophila melanogaster depends on age, sex and experience. J Neurogenet 1:113-126.

Technau G, Heisenberg M (1982) Neural reorganization during metamorphosis of the corpora pedunculata in Drosophila melanogaster. Nature 295:405-407.

Todd PK, Mack KJ (2000) Sensory stimulation increases cortical expression of the fragile X mental retardation protein in vivo. Brain Res Mol Brain Res 80:17-25.

Wan L, Dockendorff TC, Jongens TA, Dreyfuss G (2000) Characterization of dFMR1, a Drosophila melanogaster homolog of the fragile X mental retardation protein. Mol Cell Biol 20:8536-8547.

Warrick JM, Chan HY, Gray-Board GL, Chai Y, Paulson HL, Bonini NM (1999) Suppression of polyglutamine-mediated neurodegeneration in Drosophila by the molecular chaperone HSP70. Nat Genet 23:425-428.

Weiler IJ, Irwin SA, Klintsova AY, Spencer CM, Brazelton AD, Miyashiro K, Comery TA, Patel B, Eberwine J, Greenough WT (1997) Fragile X mental retardation protein is translated near synapses in response to neurotransmitter activation. Proc Natl Acad Sci USA 94:5395-5400.

Withers GS, Banker G (1998) Characterizing and studying neuronal cultures. In: Culturing nerve cells (Banker G, Goslin K, eds), pp 113-151. Cambridge, MA: MIT.

Zalfa F, Giorgi M, Primerano B, Moro A, Di Penta A, Reis S, Oostra B, Bagni C (2003) The fragile X syndrome protein FMRP associates with BC1 RNA and regulates the translation of specific mRNAs at synapses. Cell 112:317-327.

Zars T (2000) Behavioral functions of the insect mushroom bodies. Curr Opin Neurobiol 10:790-795.

Zars T, Fisher M, Schulz R, Heisenberg M (2000) Localization of a shortterm memory in Drosophila. Science 288:672-675.

Zhang YQ, Bailey AM, Matthies HJ, Renden RB, Smith MA, Speese SD, Rubin GM, Broadie K (2001) Drosophila fragile X-related gene regulates the MAP1B homolog Futsch to control synaptic structure and function. Cell 107:591-603. 